Atmos. Chem. Phys., 13, 10883-10905, 2013

www.atmos-chem-phys.net/13/10883/2013/

doi:10.5194/acp-13-10883-2013

(c) Author(s) 2013. CC Attribution 3.0 License.

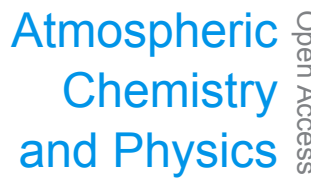

(c) (i)

\title{
Projected effects of declining aerosols in RCP4.5: unmasking global warming?
}

\author{
L. D. Rotstayn ${ }^{1}$, M. A. Collier ${ }^{1}$, A. Chrastansky ${ }^{1}$, S. J. Jeffrey ${ }^{2}$, and J.-J. Luo ${ }^{3}$ \\ ${ }^{1}$ Centre for Australian Weather and Climate Research, CSIRO Marine and Atmospheric Research, Aspendale, Vic, Australia \\ ${ }^{2}$ Department of Science, Information Technology, Innovation and the Arts, Dutton Park, Qld, Australia \\ ${ }^{3}$ Centre for Australian Weather and Climate Research, Bureau of Meteorology, Melbourne, Vic, Australia
}

Correspondence to: L. D. Rotstayn (leon.rotstayn@csiro.au)

Received: 21 June 2013 - Published in Atmos. Chem. Phys. Discuss.: 11 July 2013

Revised: 1 October 2013 - Accepted: 11 October 2013 - Published: 7 November 2013

Abstract. All the representative concentration pathways (RCPs) include declining aerosol emissions during the 21st century, but the effects of these declines on climate projections have had little attention. Here we assess the global and hemispheric-scale effects of declining anthropogenic aerosols in RCP4.5 in CSIRO-Mk3.6, a model from the Coupled Model Intercomparison Project Phase 5 (CMIP5). Results from this model are then compared with those from other CMIP5 models.

We calculate the aerosol effective radiative forcing (ERF, including indirect effects) in CSIRO-Mk3.6 relative to 1850 , using a series of atmospheric simulations with prescribed sea-surface temperatures (SST). Global-mean aerosol ERF at the top of the atmosphere is most negative in 2005 $\left(-1.47 \mathrm{~W} \mathrm{~m}^{-2}\right)$. Between 2005 and 2100 it increases by $1.46 \mathrm{~W} \mathrm{~m}^{-2}$, i.e., it approximately returns to 1850 levels. Although increasing greenhouse gases (GHGs) and declining aerosols both exert a positive ERF at the top of the atmosphere during the 21 st century, they have opposing effects on radiative heating of the atmosphere: increasing GHGs warm the atmosphere, whereas declining aerosols cool the atmosphere due to reduced absorption of shortwave radiation by black carbon (BC).

We then compare two projections for 2006-2100, using the coupled atmosphere-ocean version of the model. One (RCP45) follows the usual RCP4.5; the other (RCP45A2005) has identical forcing, except that emissions of anthropogenic aerosols and precursors are fixed at 2005 levels. The globalmean surface warming in RCP 45 is $2.3^{\circ} \mathrm{C}$ per $95 \mathrm{yr}$, of which almost half $\left(1.1^{\circ} \mathrm{C}\right)$ is caused by declining aerosols. The warming due to declining aerosols is almost twice as strong in the Northern Hemisphere as in the Southern Hemisphere, whereas that due to increasing GHGs is similar in the two hemispheres.

For precipitation changes, the effects of declining aerosols are larger than those of increasing GHGs due to decreasing atmospheric absorption by black carbon: $63 \%$ of the projected global-mean precipitation increase of $0.16 \mathrm{~mm}$ per day is caused by declining aerosols. In the Northern Hemisphere, precipitation increases by $0.29 \mathrm{~mm}$ per day, of which $72 \%$ is caused by declining aerosols.

Comparing 13 CMIP5 models, we find a correlation of -0.54 (significant at $5 \%$ ) between aerosol ERF in the present climate and projected global-mean surface warming in RCP4.5; thus, models that have more negative aerosol ERF in the present climate tend to project stronger warming during 2006-2100. A similar correlation $(-0.56)$ is found between aerosol ERF and projected changes in global-mean precipitation.

These results suggest that aerosol forcing substantially modulates projected climate response in RCP4.5. In some respects, the effects of declining aerosols are quite distinct from those of increasing GHGs. Systematic efforts are needed to better quantify the role of declining aerosols in climate projections.

\section{Introduction}

It has been broadly understood for more than two decades that anthropogenic aerosols (AAs) have masked the warming effects of increasing greenhouse gases, and that efforts 
to reduce aerosol concentrations are likely to exacerbate future increases of global-mean temperature (Wigley, 1989). However, aerosol effects are very uncertain, especially when aerosol indirect effects are considered. For example, just for the cloud-albedo effect in liquid-water clouds (the first indirect effect), Forster et al. (2007) gave an estimated $95 \%$ uncertainty range of -0.3 to $-1.8 \mathrm{Wm}^{-2}$ in the global mean.

In the Coupled Model Intercomparison Project Phase 5 (CMIP5; Taylor et al., 2012), future projections are based on four representative concentration pathways (RCPs). A feature of all of these is that emissions of aerosols and aerosol precursors decline sharply in the 21st century (Lamarque et al., 2011). Although some of the earlier Special Report on Emissions Scenarios (SRES; Nakicenovic et al., 2000) did incorporate substantial decreases in sulfur dioxide emissions, these decreases are much larger in the RCPs (Van Vuuren et al., 2011). Combined with an increase in the number of models that treat indirect aerosol effects, this may translate into a larger inter-model spread of projected climate change in CMIP5 than in CMIP3. This has already been noted with regard to historical simulations: Jones et al. (2013) found a wider spread of simulated historical temperature changes in CMIP5 than in CMIP3, and attributed this to more sophisticated aerosol treatments in the newer models.

Most simulations of the effects of AAs on climate have focused on the historical period, when AAs have generally been increasing. A key finding from these studies is that aerosols cannot be characterised as a "negative greenhouse gas", which simply masks some of the effects of increasing long-lived greenhouse gases (GHGs). Aerosol forcing is spatially inhomogeneous, and this can induce dynamic effects on circulation due to gradients in the forcing (Rotstayn and Lohmann, 2002a). In terms of large-scale circulation, the dynamic effect of historically increasing aerosol has been described as a southward shift of the Intertropical Convergence Zone (Rotstayn et al., 2000; Williams et al., 2001), or a weakening of the upward branch of the Hadley circulation in the Northern Hemisphere $(\mathrm{NH})$ and a strengthening of the upward branch in the Southern Hemisphere (SH) (Ming and Ramaswamy, 2011). These changes can be explained as the response to a change in the meridional surface temperature gradient (Rotstayn et al., 2000; Williams et al., 2001), or the inter-hemispheric asymmetry in aerosol forcing, for which the atmospheric circulation partially compensates (Kang et al., 2009; Ming and Ramaswamy, 2011; Chiang and Friedman, 2012).

Climate modelling also suggests large regional impacts on circulation and rainfall from historical increases in AAs. There is evidence that AA-induced circulation changes have affected rainfall in South Asia (Ramanathan et al., 2005; Meehl et al., 2008; Bollasina et al., 2011), East Asia (Menon et al., 2002; Cheng et al., 2005; Liu et al., 2011) and the Sahel (Rotstayn and Lohmann, 2002a; Kawase et al., 2010; Ackerley et al., 2011). Booth et al. (2012) found that in the HadGEM2-ES climate model, aerosols were the most im- portant driver of 20th century North Atlantic SST variability, although Chiang and Friedman (2012) concluded that the relative importance of natural variability and anthropogenic forcing is still uncertain. Most studies of these effects have focused on the $\mathrm{NH}$, but there is also evidence that changes in AAs can alter circulation in the SH (e.g., Rotstayn et al., 2012, 2013).

Such large effects in simulations of historical changes in AAs suggest that there will also be substantial effects due to declining aerosols in 21 st century projections. Prior to CMIP5, Kloster et al. (2010) found substantial effects on temperature and precipitation due to a maximum feasible abatement of aerosols in equilibrium climate simulations for the year 2030. The effects of declining aerosols in 21st century projections in CMIP5 are likely to be larger than they were in CMIP3, due to larger decreases of emissions, and an increase in the proportion of models that include indirect aerosol effects (e.g., Levy et al., 2013). Chalmers et al. (2012) found that the near-term warming projected under RCP2.6 in the HadGEM2-ES model is greater than under RCP4.5, even though the greenhouse-gas forcing is weaker in RCP2.6; they attributed the greater warming to a rapid and substantial decrease of sulfur emissions in RCP2.6. In contrast, Gillett and Von Salzen (2013) found that the contribution of aerosol reductions to projected warming between 2000 and 2040 in the CanESM2 model is relatively modest (about $30 \%$ ).

The above arguments indicate a need for a systematic effort to quantify the role of declining AAs in projections of 21 st century climate. A similar point was made by Villarini and Vecchi (2012). They found that over the first half of the 21 st century, radiative forcing changes increased the frequency of tropical cyclones over the North Atlantic in CMIP5 projections, and this increase probably arose from decreasing aerosols. They also highlighted the need for coordinated experiments that isolate the effects of different forcing agents, because they were unable to test this hypothesis across the full set of CMIP5 models.

The most direct way to isolate the effects of projected aerosol changes is to run simulations that are similar to the standard RCPs, except that AA emissions are held fixed. This approach was recently adopted by Levy et al. (2013), who compared simulations forced by RCP4.5 with a modified RCP4.5 in which AA emissions were fixed at their 2005 values. Among other things, they found that declining aerosols in their model caused about $1{ }^{\circ} \mathrm{C}$ of extra warming by 2100 in RCP4.5.

Here we consider the effects of declining aerosols in RCP4.5 in a CMIP5 climate model (CSIRO-Mk3.6), by comparing two projections for the period 2006-2100. One experiment follows the usual RCP4.5, whereas the other has identical forcing, except that emissions of AAs and their precursors are held fixed at 2005 levels; the difference between these two experiments gives the simulated effects of declining AAs. We assess the aerosol radiative forcing and compare 
global- and hemispheric-scale changes in surface temperature and precipitation induced by declining AAs and increasing greenhouse gases. We also assess these changes in other CMIP5 models for which calculations of aerosol radiative forcing are available.

\section{Model and simulations}

\subsection{Model description}

CSIRO Mark 3.6 (CSIRO-Mk3.6) is a coupled atmosphereocean global climate model (GCM) with dynamic sea ice. The main differences between Mk3.6 and its predecessor $(\mathrm{Mk} 3.5)$ are the inclusion of an interactive aerosol treatment, an updated radiation scheme, and a revised boundary-layer scheme in Mk3.6. The atmospheric model has 18 vertical levels and horizontal resolution of approximately $1.875^{\circ} \times$ $1.875^{\circ}$ (spectral T63). The aerosol scheme treats sulfate, organic aerosol (OA), black carbon (BC), dust and sea salt. The model and the forcing data used for CMIP5 are described by Rotstayn et al. (2012), with a particular focus on the aerosol treatments; earlier versions are described by Gordon et al. $(2002,2010)$. The ocean and sea-ice models are unchanged between Mk3.5 and Mk3.6. The ocean model has 31 vertical levels and horizontal resolution of approximately $0.9375^{\circ}$ (latitude) by $1.875^{\circ}$ (longitude); see Gordon et al. (2010) for further details.

Here we briefly describe aspects of the aerosol scheme that are most relevant to the present study. Although feedbacks involving dust and sea salt can occur, our focus is mainly on species with anthropogenic sources (sulfate, OA and BC); readers are referred to Rotstayn et al. (2012) for further details of the dust and sea-salt treatments. Carbonaceous aerosols and the sulfur cycle are treated by a single-moment ("bulk") prognostic scheme: tracers are the mass mixing ratios of dimethyl sulfide (DMS), sulfur dioxide $\left(\mathrm{SO}_{2}\right)$, sulfate, and hydrophobic and hydrophilic forms of OA and BC. The treatment of tropospheric sulfur chemistry is based on Feichter et al. (1996) and Rotstayn and Lohmann (2002b). Oxidant fields needed for the sulfur cycle are prescribed for the present climate (Feichter et al., 1996). The carbonaceous aerosol module (Cooke et al., 1999) is rather simple, and does not explicitly treat chemical reactions; rather, it assumes a fixed e-folding time of 1 day for the "ageing" of OA and $\mathrm{BC}$ from their hydrophobic to hydrophilic forms. The ratio of OA to organic carbon is set to 1.3 .

Anthropogenic and biomass-burning emissions of sulfur, OA and BC are based on Lamarque et al. (2010, 2011), except that we uniformly increased the emissions of BC by $25 \%$ and OA by $50 \%$ (Rotstayn et al., 2012). We justified the $\mathrm{BC}$ increase by the large uncertainty in current emission inventories, and the underestimate of aerosol atmospheric heating in current GCMs (e.g., Shindell et al., 2013a). The rationale for the OC increase was the model's underestimate of aerosol optical depth (AOD) in biomass-burning regions, and the omission of secondary OA from biomass burning and anthropogenic sources in the standard inventory; such secondary aerosol formation can substantially enhance effective emissions of OA (e.g., Lee et al., 2008). After these adjustments, the annual year- 2000 emission of $\mathrm{BC}$ is $9.7 \mathrm{Tg}$, and the emission of $\mathrm{OA}$ from biomass-burning and anthropogenic sources is $53 \mathrm{Tg} \mathrm{C}$, both well within the uncertainty range of current estimates.

The model also includes natural sources, which are mostly constant in time. Natural sources of sulfur are $\mathrm{SO}_{2}$ from continuously erupting volcanoes and biogenic emissions of DMS from oceans and terrestrial sources. The only natural source of carbonaceous aerosol is a prescribed flux of biogenic secondary organic aerosol (Guenther et al., 1995; Rotstayn et al., 2012). Note that the oceanic DMS source is not constant in time; even though the concentration of DMS in sea water is prescribed (Kettle and Andreae, 2000), the ocean-atmosphere flux of DMS is wind-dependent.

The model uses prescribed, zonally averaged distributions of stratospheric sulfate from volcanic eruptions (Sato et al., 1993); a recent update, which extended the data set beyond 1999, was not available at the time we commenced the simulations, so we set volcanic forcing to zero from 2000 onwards. Further details are given by Rotstayn et al. (2007).

CSIRO-Mk3.6 treats the direct radiative effects of sulfate, carbonaceous aerosol (OA and $\mathrm{BC}$ ), dust and sea salt and the indirect effects of sulfate, sea salt and carbonaceous aerosol on liquid-water clouds. In the radiation scheme, OA and $\mathrm{BC}$ are assumed to be internally mixed, while other aerosol species are externally mixed. The scheme treats the shortwave effects of all the above aerosol types and the longwave effects of dust and stratospheric sulfate. The model also includes treatments of the first and second aerosol indirect effects on liquid-water clouds. The parameterization of cloud droplet number concentration as a function of the concentration of hydrophilic aerosols is based on Jones et al. (2001); hydrophilic aerosols are assumed to be sulfate, sea salt and (internally mixed) hydrophilic carbonaceous aerosol. The calculation of the first indirect effect follows Rotstayn and Liu (2009). The second indirect aerosol effect (sometimes called the cloud-lifetime effect) enters the model via the calculation of warm-rain formation (autoconversion) in liquidwater stratiform clouds (Rotstayn and Liu, 2005). Note that the calculation of cloud fraction, and ice-cloud properties in general, do not depend on aerosols in any way (Rotstayn, 1997, 1999). Further details of the treatments of aerosolradiation and aerosol-cloud interactions are given by Rotstayn et al. (2007, 2012).

Rotstayn et al. (2012) evaluated the present-day aerosol simulation with regard to observations and other models. They found that the global-mean aerosol burdens and anthropogenic (2000 minus 1850) AODs in the CSIRO-Mk3.6 present-day simulation from CMIP5 were larger than the average of earlier models, such as those from AeroCom (Kinne 
et al., 2006; Schulz et al., 2006), though they were not outside the range of these results. In a recent intercomparison, Shindell et al. (2013a) found that mid-visible, clear-sky (allsky) AODs in CSIRO-Mk3.6 were biased high with respect to satellite retrievals, by an average of $21 \%$ (13\%) compared to MODIS and $16 \%(7 \%)$ compared to MISR. Some of the high bias is likely due to large dust AODs, rather than anthropogenic AODs (Rotstayn et al., 2011). Two other models also showed a high bias relative to satellite-retrieved AODs, whereas five models showed a low bias. Considering the spatial pattern, CSIRO-Mk3.6 clear-sky AODs had correlations with MODIS and MISR retrievals of 0.62 and 0.64 , respectively, which was slightly better than the average of the other models in Shindell et al. (2013a).

\subsection{Simulations}

A substantial number of transient experiments were performed with CSIRO-Mk3.6 as part of CMIP5 (Jeffrey et al., 2013); these included the standard historical experiment with "all forcings", a range of historical experiments driven by changes in individual forcing agents, and projections driven by the four RCPs. Here we use the following experiments, each of which is a 10-member ensemble:

- HIST: standard historical run for 1850-2005 with "all forcings", namely long-lived GHGs, ozone, AAs, volcanic and solar forcing.

- RCP45: projection for 2006 to 2100 based on RCP4.5, a medium-low emission pathway in which total radiative forcing is stabilized before 2100 at roughly $4.5 \mathrm{~W} \mathrm{~m}^{-2}$ (Thomson et al., 2011); further details are given in the next paragraph.

- RCP45A2005: same as RCP45, except that emissions of AAs and their precursors are held fixed at 2005 values. To simplify the terminology, AAs include aerosols from biomass burning.

RCP45 is forced by changes in (1) annual-mean concentrations of long-lived GHGs (carbon dioxide, methane, nitrous oxide and chlorofluorocarbons), (2) annual-mean concentrations of ozone (Cionni et al., 2011), and (3) emissions of AAs and their precursors $\left(\mathrm{SO}_{2}, \mathrm{OA}\right.$ and $\left.\mathrm{BC}\right)$. There is also a simple representation of the $11 \mathrm{yr}$ solar cycle, and a small implied positive forcing (relative to the historical period) due to the assumption of zero volcanic forcing after 2000. Further details of the experimental design and radiative forcings are given by Rotstayn et al. (2012) and Jeffrey et al. (2013).

RCP45A2005 has not been published as part of the CSIRO-Mk3.6 CMIP5 submission, but it uses the same code and experimental design as the other experiments. We shall refer to climatic changes in RCP45A2005 as "GHGinduced", noting that this includes the effects of increasing long-lived GHGs and changes in tropospheric and stratospheric ozone concentrations. Changes in tropospheric ozone are relatively small in RCP4.5 (Shindell et al., 2013a). While the recovery of stratospheric ozone can be important for mid-latitude dynamics, especially in the SH (Arblaster et al., 2011), we expect the effects to be modest for global and hemispheric-scale changes in temperature and precipitation, which is our main focus here.

The effects of declining AAs are diagnosed from RCP45 minus RCP45A2005. Some aspects of the response are likely to be non-linear, in the sense that RCP45 minus RCP45A2005 is not identical to an experiment forced only by declining AAs after 2005; this has been seen for historical changes of AAs in atmospheric models coupled to slab ocean models (Feichter et al., 2004; Ming and Ramaswamy, 2009).

We will refer, in passing, to the following transient experiments, which are also 10-member ensembles:

- RCP26, RCP60 and RCP85: projections forced by the other three RCPs.

- NoAA: same as HIST, except that emissions of AAs and their precursors are held fixed at 1850 values. This experiment was extended from 2006 to 2012 using assumptions from RCP45, i.e., all forcing agents varied as in RCP45, except for AAs.

We also carried out several simulations with prescribed SSTs, designed to calculate radiative forcing for different years; these runs are similar to those used in CMIP5 to calculate aerosol forcing for 2000 relative to 1850, and are described in more detail in Sect. 3.2.

\section{Aerosol changes and radiative forcing}

\subsection{Aerosol changes}

Whereas aerosol emissions, burdens and AODs generally increased in magnitude during the 20th century, the converse applies in 21 st century projections. Time series of these quantities are shown in Fig. 1.

Global anthropogenic emissions of $\mathrm{SO}_{2}, \mathrm{OA}$ and $\mathrm{BC}$ are shown in Fig. 1a, with BC multiplied by 10 for clarity. $\mathrm{SO}_{2}$ shows the steepest increase until the 1970s, when emission controls in developed countries began to take effect (Smith et al., 2011). The increase between 2000 and 2005 is mostly due to economic growth in China (Klimont et al., 2013); note that the emission estimates are quite uncertain, e.g., $\pm 9.6 \mathrm{Tg} \mathrm{SO}_{2}$ in 2005 (Smith et al., 2011). Both $\mathrm{SO}_{2}$ and $\mathrm{BC}$ emissions peak in 2005 and show steep declines in the $21 \mathrm{st}$ century in RCP45, due to assumed decreases once national incomes reach a certain level (Smith and Bond, 2013). By 2100, global emissions of $\mathrm{SO}_{2}$ and $\mathrm{BC}$ are similar to what they were in 1900. OA emissions are dominated by open biomass burning; in relative terms the rise and fall of OA emissions appears less dramatic, although by 2100 OA emissions are slightly below their 1850 value. 


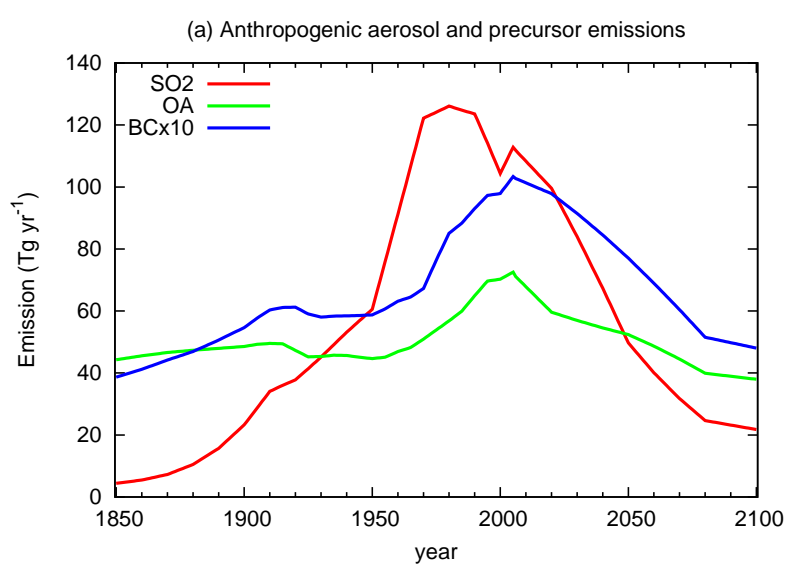

(b) Global aerosol burdens

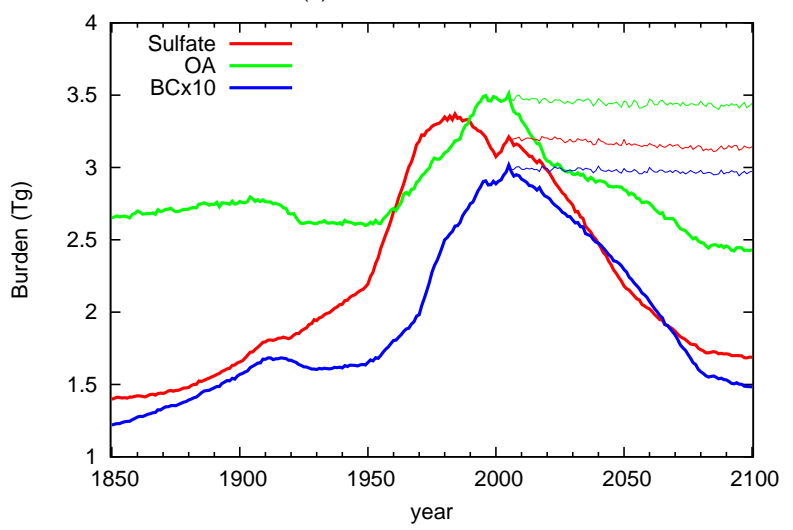

(c) Sub-micron aerosol optical depth

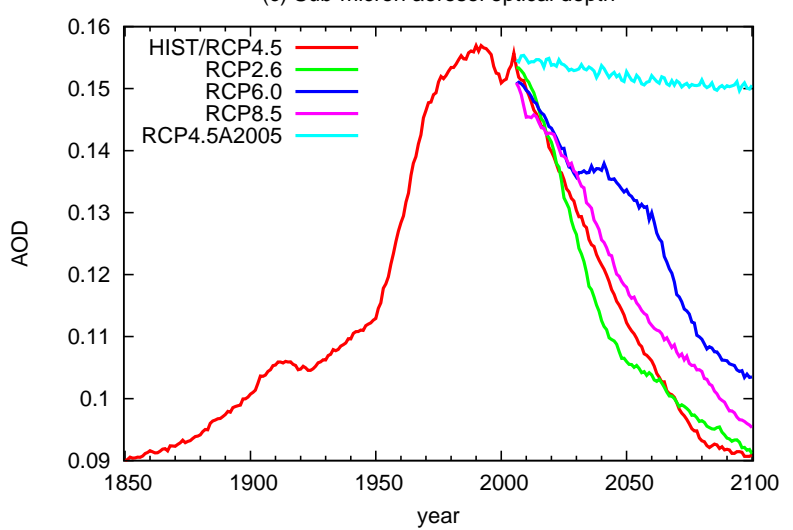

Fig. 1. Time series of global aerosol properties: (a) annual anthropogenic emissions of $\mathrm{SO}_{2}$ (red), $\mathrm{OA}$ (green) and $\mathrm{BC}$ (blue, multiplied by 10), shown as teragrams of species. (b) Annual-mean global aerosol burdens from HIST (1850-2005) and RCP45 (20062100), shown as thick lines: sulfate (red), OA (green) and BC (blue, multiplied by 10). Corresponding burdens from RCP45A2005 (2006-2100) are shown as thin lines. (c) Annual-mean sub-micron clear-sky AOD at $550 \mathrm{~nm}$ from HIST and RCP45 (red line), comprising the sum of AOD from sulfate, OA and BC. For comparison, AODs for 2006-2100 are also shown for RCP45A2005 and the other standard RCPs.
Simulated time series of global burdens of sulfate, OA and $\mathrm{BC}$ are shown in Fig. 1b, both for the historical period and the 21 st century. These are broadly consistent with the corresponding emissions, e.g., sulfate shows the steepest rise until the 1970s and declines sharply in the 21st century. By 2100, sulfate and $\mathrm{BC}$ burdens are at levels comparable to those in 1900 , whereas the OA burden is slightly below its 1850 value.

Also shown in Fig. 1b (as thin lines) are time series of global aerosol burdens in RCP45A2005. Reflecting constant anthropogenic emissions, global aerosol burdens are almost (but not entirely) flat during 2006-2100. Over $95 \mathrm{yr}$, OA shows a decrease of $\sim 1 \%$, and sulfate shows a decrease of $\sim$ $3 \%$. Use of fixed anthropogenic emissions in RCP45A2005 does not guarantee that aerosol burdens and AODs will be constant in time, even in the global mean. Aerosol burdens will be affected by changes in formation, transport and removal processes (especially rainfall). Because the treatment of carbonaceous aerosol in the model is simple, rainfall is expected to be the main relevant feedback process. The balance is more complex for sulfate, because in-cloud oxidation of $\mathrm{SO}_{2}$ is an important source of sulfate. Thus while scavenging by rainfall removes sulfate, formation of sulfate is enhanced in cloudier regions, which tend to be associated with more rainfall. The net result (for both sulfate and OA burdens) is a complex pattern of relatively small increases and decreases (not shown). As discussed below, the implications for changes in AOD are also relatively small.

Sub-micron AOD (defined here as the sum of AOD from sulfate, $\mathrm{OA}$ and $\mathrm{BC}$ ) is useful as an integrated measure of changes in these aerosol species; it is a good predictor of direct radiative forcing, but not of indirect forcing (Shindell et al., 2013a). The red curve in Fig. 1c shows time series of global-mean sub-micron AOD from HIST and RCP45. For comparison, the same field is also shown from experiments forced by the other RCPs, and from RCP45A2005. Until about 2060, RCP45 tends to lie in between RCP26 and RCP85, although by $2100 \mathrm{RCP} 45$ has the lowest AOD (slightly lower than RCP26). After about 2030, the outlier is RCP60, which has a relatively weak decline in sub-micron AOD.

With fixed anthropogenic emissions, RCP45A2005 shows a small decline in global-mean sub-micron AOD $(\sim 4 \%$ during 2006-2100). This is a little larger than the relative declines in the sulfate and OA burdens, most likely due to changes in simulated relative humidity: AOD for sulfate and hydrophilic carbonaceous aerosol increases with relative humidity in the model, and Mk3.6 simulates a decrease of nearsurface relative humidity over most land areas (not shown). This is a common feature of climate projections forced by increasing long-lived GHGs, and is probably related to the land-ocean contrast in surface warming (O'Gorman and Muller, 2010; Sherwood et al., 2010).

Figure 2 shows the spatial pattern of trends in sub-micron AOD from RCP45 and RCP45A2005. In RCP45 (panel a), 
(a) RCP45 2006-2100 sub-micron AOD trend

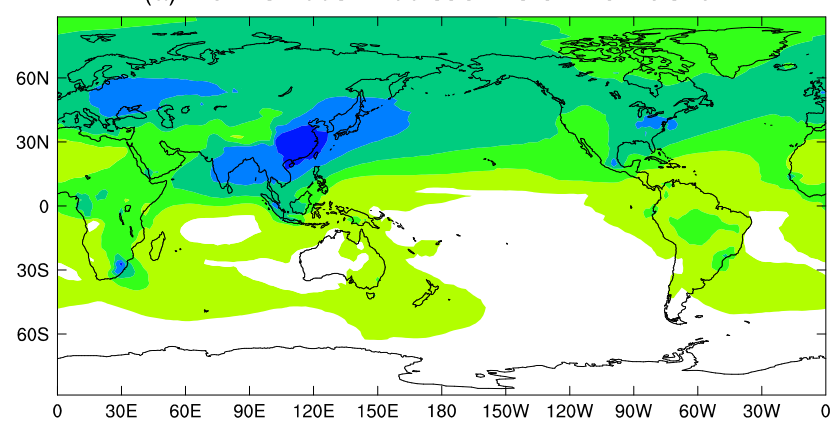

(b) RCP45A2005 2006-2100 sub-micron AOD trend

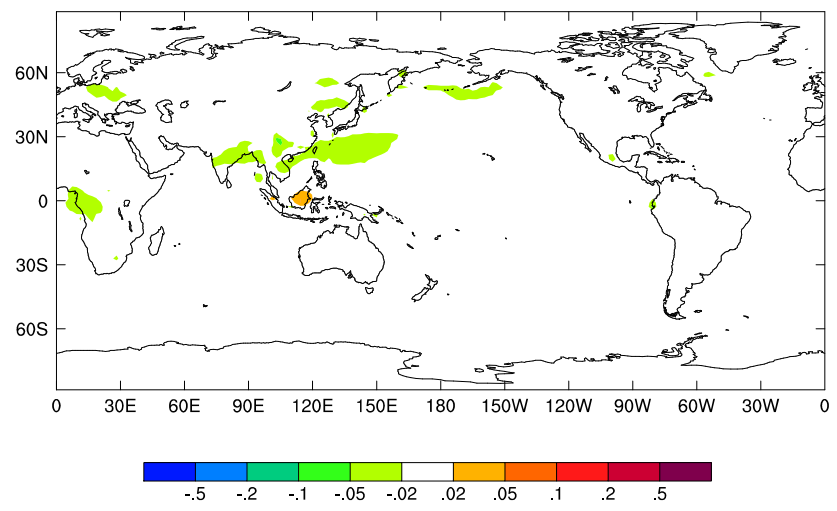

Fig. 2. 2006-2100 trends of annual-mean, sub-micron clear-sky AOD at $550 \mathrm{~nm}$ (AOD units per century) from (a) RCP45, and (b) RCP45A2005.

negative AOD trends are largest over and downwind of Asia and eastern Europe, and to a lesser extent the eastern US. Trends are much smaller over the $\mathrm{SH}$ than the NH, although the signature of biomass burning is noticeable over Africa, South America and the Indonesian region. As expected, submicron AOD trends in RCP45A2005 (panel b) are much smaller, with only a few isolated areas showing decreases between 0.02 and 0.05 per century. These generally occur over the most polluted regions, where trends in $\mathrm{RCP} 45$ are much larger. In view of this, and to simplify our arguments, we will assume that trends in AAs in RCP45A2005 can be neglected.

\subsection{Radiative forcing}

Calculations of aerosol radiative forcing help to put the simulated response (discussed in Sect. 4) in context. We followed the method from CMIP5 by running a series of $30 \mathrm{yr}$ atmospheric simulations forced by prescribed SSTs and sea ice taken as a long-term average from the pre-industrial control run. To calculate aerosol forcing, all forcing agents (other than AAs) were held at 1850 values, while emissions of AAs and their precursors were in turn set to values for the appropriate year. We did runs with AA emissions for the years 1850, 1930, 1980, 2000, 2005, 2030, 2060 and 2100, respec- tively (following RCP4.5 after 2005). There is one minor difference in the experimental setup compared to the runs we did for CMIP5: whereas no spinup period was used in the CMIP5 runs, the current runs have a six-month spinup. Since aerosols have an atmospheric lifetime of a few days to weeks, this allows ample time for aerosol burdens to adjust in response to changes in emissions.

The difference in the net (shortwave and longwave) radiative flux at the top of the atmosphere (TOA) between the 1850 simulation and the simulation using AA and precursor emissions for a given year gives an estimate of the aerosol effective radiative forcing (ERF), which includes indirect effects and rapid adjustments induced by aerosol changes (Shindell et al., 2013a). We also calculated aerosol direct radiative forcing for each of the listed years using a double call to the shortwave radiation scheme; one call uses aerosols for the year in question, and the other call uses zero aerosols. (Note that the double call is needed only for the shortwave scheme, because longwave direct radiative effects are not treated for aerosols with anthropogenic sources.) The same approach as used for the TOA can be applied to obtain aerosol ERF or direct radiative forcing at the surface; then the difference between the TOA and surface forcing gives the atmospheric radiative heating.

While global-mean TOA ERF is useful as a predictor of global-mean temperature change, atmospheric radiative heating is important for understanding changes in global precipitation. This is because the precipitation response includes a fast atmospheric adjustment to the radiative forcing, plus a slower response that is roughly proportional to temperature change (Andrews et al., 2010). The fast precipitation response is negative for forcing agents that cause positive atmospheric radiative heating, such as increasing long-lived GHGs or BC, because the atmosphere adjusts to the perturbation by reducing the release of latent heat associated with precipitation ( $L \Delta P$; Andrews et al., 2010; Ming et al., 2010). The slow increase of precipitation with increasing temperature occurs because a warmer atmosphere loses energy by increased emission of longwave radiation. In this case, the atmosphere substantially adjusts to the radiative perturbation by increasing the release of latent heat $(L \Delta P)$ (Allen and Ingram, 2002; Ming et al., 2010; O'Gorman et al., 2012; Allan et al., 2013).

For historically increasing aerosols, both the fast and slow responses act to decrease global-mean precipitation (Ming et al., 2010). As a consequence, the hydrological sensitivity (the change in global-mean precipitation per unit change in global-mean surface temperature) is larger for aerosol forcing than for long-lived GHG forcing. This has also been discussed in the context of declining aerosols in near-term climate projections (Kloster et al., 2010).

Surface radiative forcing is also an important indicator of changes in the hydrological cycle (e.g., Roderick and Farquhar, 2002). In particular, changes in net radiation at the surface are substantially offset by changes in the latent heat 


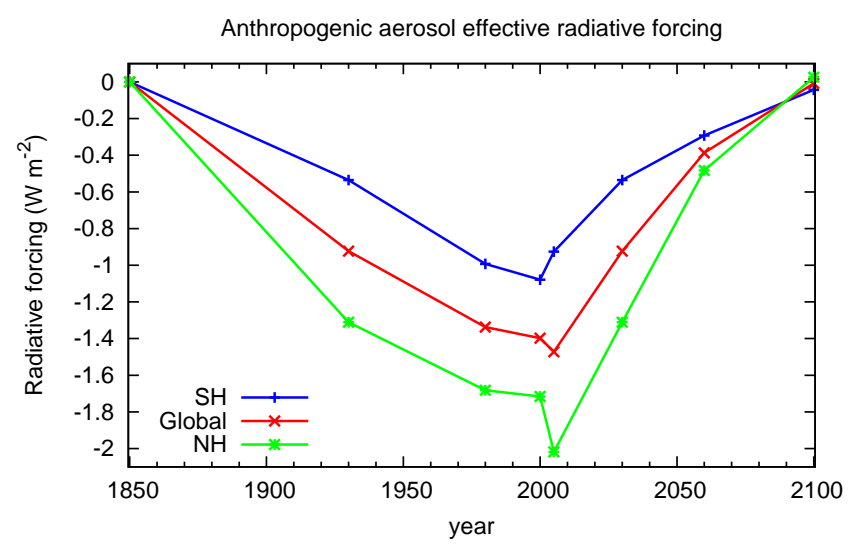

Fig. 3. Anthropogenic aerosol effective radiative forcing for the historical period and RCP4.5, averaged over the SH (blue line), the globe (red line) and the $\mathrm{NH}$ (green line). Calculations are for years 1850, 1930, 1980, 2000, 2005, 2030, 2060 and 2100, with linear interpolation in between.

flux, which in turn are linked to changes in global precipitation (Liepert et al., 2004; Andrews et al., 2009; Kloster et al., 2010). This is another way to explain the larger hydrological sensitivity for aerosol forcing compared to long-lived GHG forcing.

For comparison with the aerosol ERF, we also calculated ERF due to changes in long-lived GHGs for 2005 and 2100. These runs are analogous to the runs used to calculate aerosol forcing: concentrations of long-lived GHGs are set to values for 2005 or 2100 , respectively, while other anthropogenic forcings (aerosol emissions and ozone concentrations) are held at 1850 levels.

Global- and hemispheric-mean values of aerosol ERF (relative to 1850) are plotted in Fig. 3 for 1930, 1980, 2000, 2005, 2030, 2060 and 2100. The global-mean aerosol ERF in 2000 is $-1.40 \pm 0.09 \mathrm{~W} \mathrm{~m}^{-2}$ (where this indicative error range is a $95 \%$ confidence interval based on a $t$ test). As discussed in Sect. 5, other CMIP5 models that include indirect aerosol effects have global-mean aerosol ERF ranging from -0.76 to $-1.62 \mathrm{~W} \mathrm{~m}^{-2}$. This indicates that CSIROMk3.6 has stronger than average aerosol ERF, though it is well within the range of results from CMIP5 models.

Global-mean aerosol ERF in Fig. 3 is slightly more negative in 2000 than in 1980, despite lower $\mathrm{SO}_{2}$ emissions in 2000. This reflects a net negative contribution to aerosol ERF from carbonaceous aerosols in CSIRO-Mk3.6. Calculations similar to the above indicate that the year-2000 ERF solely from sulfate is $-1.10 \mathrm{~W} \mathrm{~m}^{-2}$ in CSIRO-Mk3.6, implying that carbonaceous aerosols contribute about $-0.3 \mathrm{Wm}^{-2}$ (for 2000 relative to 1850). As discussed by Rotstayn et al. (2012), inclusion of hydrophilic OA in the aerosol mass concentration used in parameterization of the cloud droplet concentration causes a substantial indirect aerosol effect due to $\mathrm{OA}$. This effect may be overestimated in our runs, given that the hygroscopicity of aged biomass-burning aerosol (which is substantially comprised of OA) is generally smaller than that of sulfate (Andreae and Rosenfeld, 2008). Results from the Atmospheric Chemistry and Climate Model Intercomparison Project (ACCMIP) also indicate more negative aerosol ERF in 2000 than in 1980, but there were only three models used for 1980 (Shindell et al., 2013a, their Fig. 18). There is little consensus among global models regarding the relative contributions of sulfate and OA to ERF; we shall return to this point in Sect. 5 .

Global-mean aerosol ERF is most negative in 2005, when it reaches $-1.47 \mathrm{~W} \mathrm{~m}^{-2}$. Stronger aerosol ERF in 2005 relative to 2000 is qualitatively consistent with the increase of $\mathrm{SO}_{2}$ emissions seen in Fig. 1a; however, 2005 aerosol ERF is within the $95 \%$ uncertainty range of the 2000 value. Relative to 2005, global-mean aerosol ERF is $+1.46 \mathrm{~W} \mathrm{~m}^{-2}$ in 2100 , i.e., it has roughly returned to its 1850 value. Note that aerosol ERF continues to become more positive after 2060, consistent with declining emissions and burdens (Fig. 1). This differs from the nominal RCP4.5 radiative forcing, which is fairly flat after 2060 (Thomson et al., 2011, their Fig. 2), because aerosol indirect effects were not included in their modelling.

With reference to Fig. 1, we note that global $\mathrm{SO}_{2}$ and $\mathrm{BC}$ emissions and sulfate and $\mathrm{BC}$ burdens are somewhat higher in 2100 than in 1850, whereas global OA emissions and burden are lower in 2100 than 1850 . Thus the effect of sulfate alone would be to give a net negative ERF in 2100 relative to 1850 , whereas $\mathrm{OA}$ and $\mathrm{BC}$ would give a net positive ERF (assuming negative ERF from OA, and positive ERF from $\mathrm{BC})$. This suggests that $\mathrm{OA}$ and $\mathrm{BC}$ changes contribute to the return of aerosol ERF to its 1850 value by 2100 . It is also consistent with the discussion above, in which we noted that carbonaceous aerosol causes net negative ERF in 2000 in CSIRO-Mk3.6.

As previously mentioned, stronger aerosol effects in 2005 than 2000 are mostly due to increased emissions from China; this is reflected in the $\mathrm{NH}$ time series in Fig. 3, with a change from $-1.72 \mathrm{~W} \mathrm{~m}^{-2}$ in 2000 to $-2.02 \mathrm{~W} \mathrm{~m}^{-2}$ in 2005 . Aerosol ERF is generally more negative in the $\mathrm{NH}$ than the $\mathrm{SH}$, but the difference decreases during the 21st century. By 2100, aerosol ERF in both hemispheres is similar to the respective 1850 values.

How does the spatial pattern of aerosol ERF compare in the future and historical periods? Figure 4 shows aerosol ERF for 2005 (relative to 1850), and 2100 (relative to 2005). In 2005, aerosol ERF is mostly negative, except for regions where the impact of $\mathrm{BC}$ on surface albedo is the dominant effect (the Arctic, and a smaller area over the Himalayas). Future changes in aerosol ERF resemble the inverse of the historical pattern. Some differences are evident, e.g. future positive ERF over Africa is weaker than historical negative ERF. As in the multi-model mean from ACCMIP (Shindell et al., 2013a, their Fig. 18), aerosol ERF is strong over the 
(a) 2005 minus 1850 aerosol effective radiative forcing $(-1.47 \mathrm{~W} / \mathrm{m} 2)$

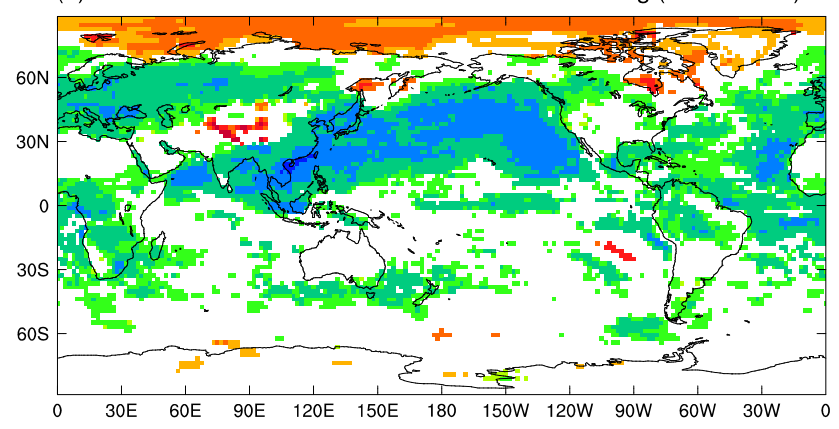

(b) 2100 minus $2005 \mathrm{RCP} 4.5$ aerosol effective radiative forcing $(+1.46 \mathrm{~W} / \mathrm{m} 2)$

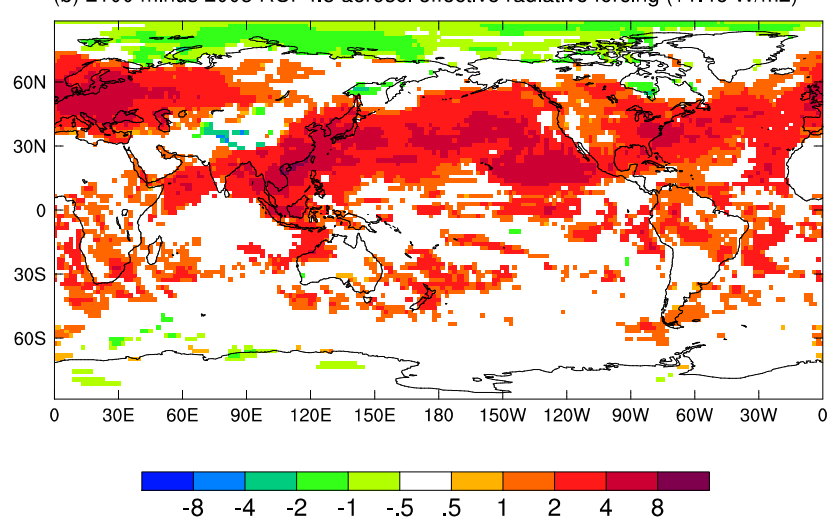

Fig. 4. Aerosol effective radiative forcing at the top of the atmosphere $\left(\mathrm{W} \mathrm{m}^{-2}\right)$ : (a) 2005 minus 1850, (b) 2100 minus 2005 . Shaded regions show ERF values that are significantly different from zero at $5 \%$, based on a two-sample $t$ test.

North Pacific, where advected aerosols interact with susceptible marine clouds.

Radiative forcing changes between 2005 and 2100 at the TOA, surface and in the atmosphere are summarised in Fig. 5 for aerosols and long-lived GHGs. For clarity, we omit ozone forcing, which is relatively small in RCP4.5 (Shindell et al., 2013a). At the TOA, global-mean ERF due to increasing long-lived GHGs is $+1.54 \mathrm{~W} \mathrm{~m}^{-2}$, slightly larger than that due to declining aerosols in CSIRO-Mk3.6 (panel a). An important difference between aerosols and long-lived GHGs is that, in the atmosphere, declining BC causes aerosol ERF to be negative $\left(-0.86 \mathrm{~W} \mathrm{~m}^{-2}\right)$, as opposed to positive ERF (atmospheric warming) for increasing long-lived GHGs $\left(+1.00 \mathrm{~W} \mathrm{~m}^{-2}\right)$. This implies that the "fast" precipitation response in RCP45 is negative for increasing long-lived GHGs and positive for declining aerosols; as we shall show in Sect. 4.2, this is reflected in a stronger response of global precipitation to declining aerosols. Also, the positive surface forcing due to declining aerosols is much larger than that due to increasing long-lived GHGs, which is also consistent with a stronger precipitation response in the aerosol case.

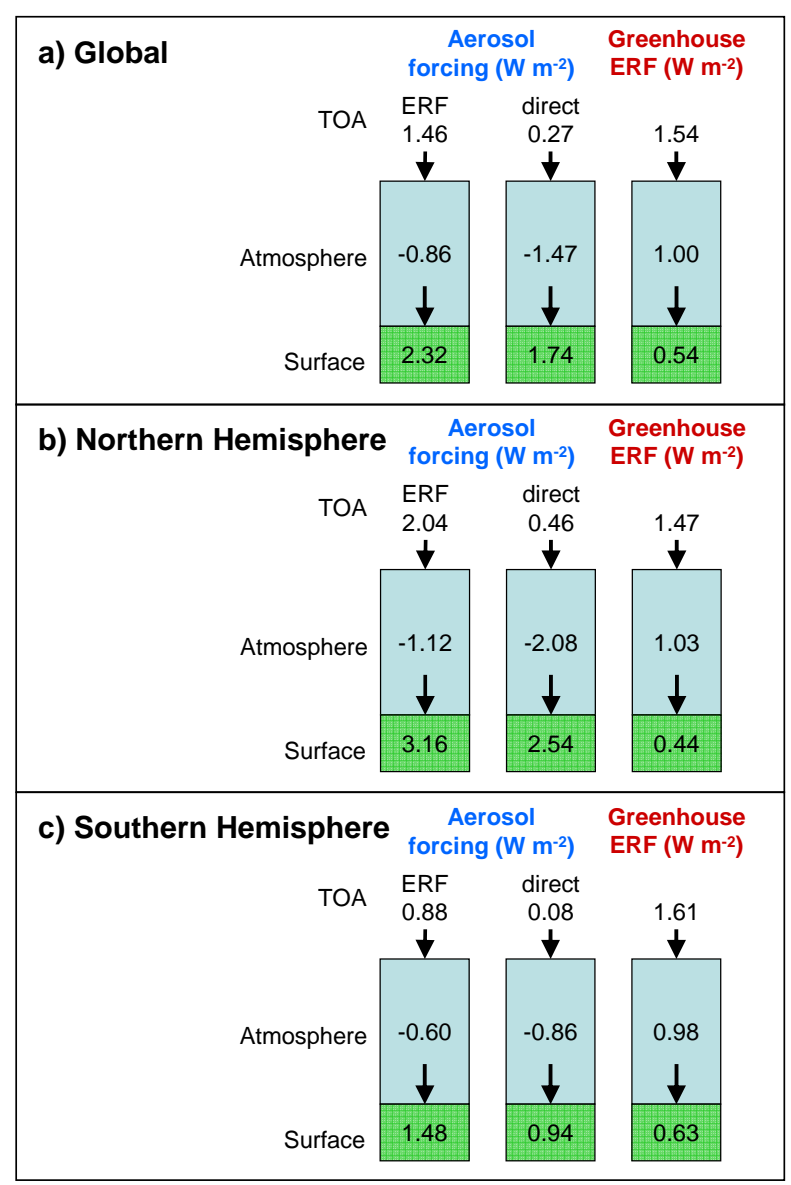

Fig. 5. Radiative forcing at the TOA, in the atmosphere, and at the surface for 2100 minus 2005 in RCP4.5, calculated from fixed-SST simulations: (a) global-mean, (b) Northern Hemisphere, (c) Southern Hemisphere. The first two columns show the total aerosol ERF and the (instantaneous) direct radiative forcing. The third column shows the ERF for long-lived GHGs.

An interesting aspect of the atmospheric cooling induced by declining aerosols is that the ERF $\left(-0.86 \mathrm{~W} \mathrm{~m}^{-2}\right)$ is substantially weaker than the instantaneous direct effect $\left(-1.47 \mathrm{~W} \mathrm{~m}^{-2}\right)$. The shortwave component of the ERF is $-1.26 \mathrm{~W} \mathrm{~m}^{-2}$, which is closer to the instantaneous value, but is still weaker by roughly $0.2 \mathrm{~W} \mathrm{~m}^{-2}$. The difference is most substantial over East and Southeast Asia (not shown), where lower aerosol levels in the 2100 run strengthen the monsoon by perturbing the land-sea surface temperature gradient. This increases the column water vapour in this region, which increases atmospheric absorption of shortwave radiation. Cloud cover also increases, and this may enhance the effect by increasing multiple reflections between cloud layers. This perturbation of the land-sea surface temperature gradient may be (at least in part) artificial, since SSTs are fixed, while land-surface temperatures can change in these runs.

There is also a longwave adjustment of $+0.40 \mathrm{~W} \mathrm{~m}^{-2}$ in the atmospheric ERF; this comprises a reduction of outgoing 
a) Global average near-surface temperature

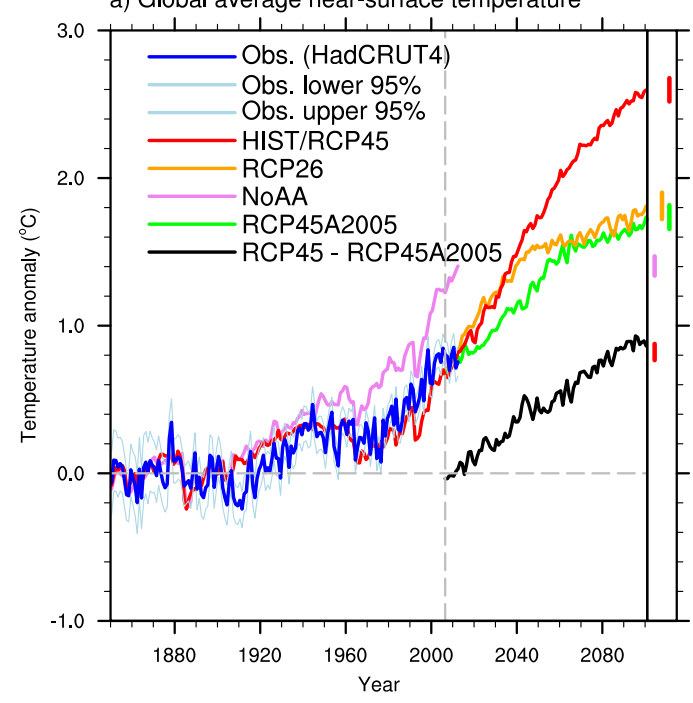

b) Hemispheric average near-surface temperature

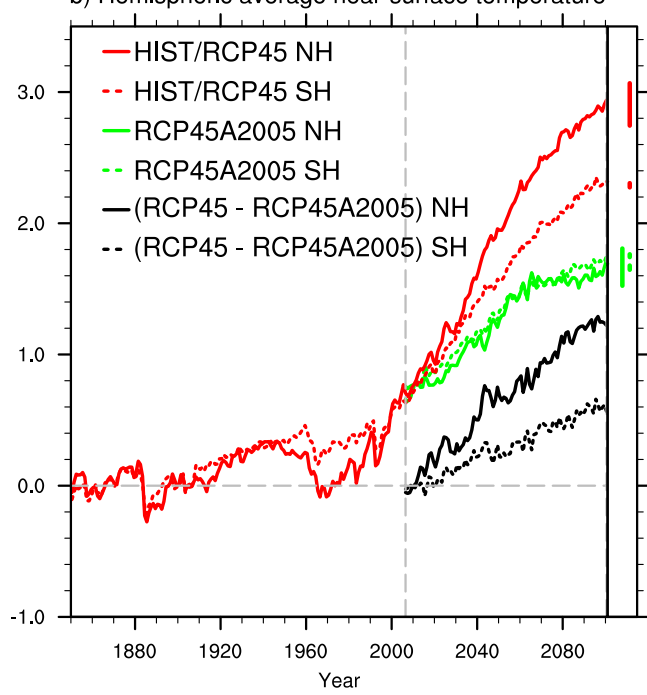

Fig. 6. (a) Anomalies (relative to the 1850-1899 mean) of annual-mean, ensemble-mean near-surface temperature: (a) global means, (b) NH and SH means. In panel a, the thick blue curve shows observations for 1850-2012 (HadCRUT4; Morice et al., 2012). The thin light blue curves denote $95 \%$ uncertainty bounds for the observations. In both panels, differences between RCP45 and RCP45A2005 are shown as black curves, and the vertical dashed line at 2006 marks the start of the projections. The vertical bars in the right inset show the standard deviations of the mean temperature from the last $10 \mathrm{yr}$ of each experiment (2091-2100 for the projections, or 2003-2012 for HIST and NoAA).

longwave radiation $\left(+0.13 \mathrm{~W} \mathrm{~m}^{-2}\right)$ due to a cooler atmosphere in response to reduced $\mathrm{BC}$ absorption, and net atmospheric warming at the lower boundary $\left(+0.27 \mathrm{~W} \mathrm{~m}^{-2}\right)$, due to a cooler atmosphere and warming of the land-surface. The warmer surface may be seen as a limitation of the experimental design in the fixed-SST experiments, rather than a physically meaningful fast adjustment. Arguably, the ideal experimental design for evaluating aerosol ERF would use fixed SSTs and fixed land-surface temperatures, as demonstrated in a simplified GCM by Shine et al. (2003). However, implementing fixed land-surface temperatures in a consistent way is impractical (or at least difficult) for more complex climate models.

Figure 5 also shows the calculated radiative forcing for the NH and SH. The TOA ERF due to increasing long-lived GHGs is slightly smaller in the NH than in the SH, due to the larger proportion of land in the $\mathrm{NH}$, which causes the atmosphere there to warm slightly due to a warmer land surface. Aerosol ERF is roughly twice as large in the $\mathrm{NH}$ as in the $\mathrm{SH}$. This was previously shown for the TOA in Fig. 3, but Fig. 5 shows that this is also the case at the surface and in the atmosphere.

We did one further fixed-SST run to calculate the RCP4.5 "all forcing" ERF in 2100, i.e. aerosol emissions, ozone and long-lived GHG concentrations were all set to $2100 \mathrm{lev}$ els. Relative to 1850 , this gave a TOA ERF of $3.87 \mathrm{~W} \mathrm{~m}^{-2}$. This is somewhat less than the nominal RCP4.5 forcing of $4.5 \mathrm{~W} \mathrm{~m}^{-2}$ (Thomson et al., 2011), but it agrees well with the multi-model mean ERF for 2095 from Forster et al. (2013).
They noted that ERF (which they calculated using the regression method, not fixed-SST runs) is generally less than radiative forcing, probably due to cloud adjustments.

\section{Global and hemispheric climate response}

In this section, we discuss simulated global and hemispheric changes in near-surface temperature and precipitation, with a primary focus on RCP4.5. Changes are quantified in terms of the least-squares trend, multiplied by the time period.

\subsection{Surface temperature changes}

Figure 6 a shows anomalies of global-mean, near-surface temperature $T_{\mathrm{s}}$ from the model and observations from HadCRUT4 (Morice et al., 2012). Prior to about 1980, the HIST ensemble mean mostly lies within the observational uncertainty, except for a period in the early 20th century, when the model appears to be too warm. The plotted curves do not show the range of the 10-member ensembles; these are shown by 2012. HIST somewhat underestimates the observed warming towards the end of the historical period, although the model catches up in the last few years, due to the "hiatus" in the observed warming. In contrast, the NoAA ensemble mean (without the cooling effect of increasing AAs) substantially overestimates the increase in $T_{\mathrm{s}}$.

In the 21 st century, the difference between RCP45 and RCP45A2005 (black curve) shows that the warming effect of declining AAs is roughly $1^{\circ} \mathrm{C}$ by 2100 ; this is similar to the 

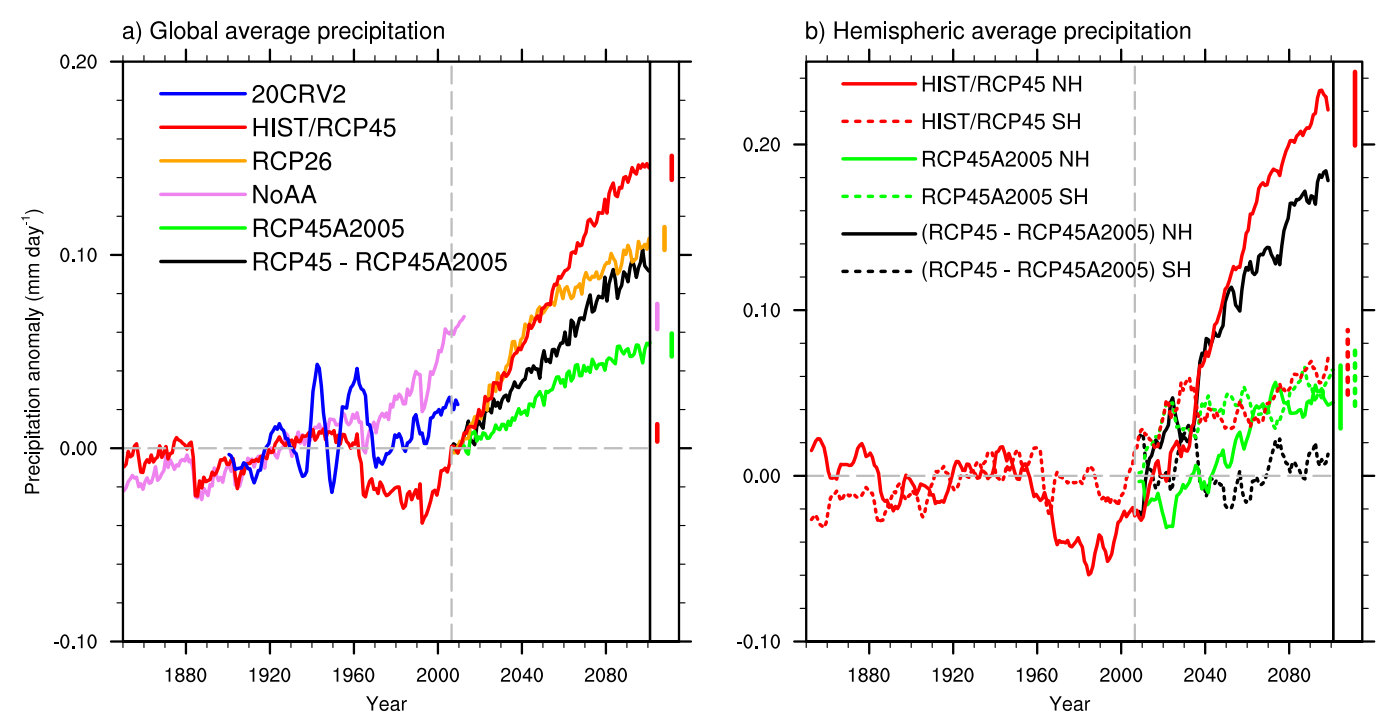

Fig. 7. Anomalies (relative to the 1850-1899 mean) of annual-mean, ensemble-mean precipitation from the model: (a) global means, (b) NH and SH means. In panel (a), the blue curve shows a reconstruction of global-mean precipitation anomalies for 1900-2009 (20CRv2; Compo et al., 2011). In both panels, differences between RCP45 and RCP45A2005 are shown as black curves, and the vertical dashed line at 2006 marks the start of the projections. The vertical bars in the right inset show the standard deviations of the mean precipitation from the last $10 \mathrm{yr}$ of each experiment (2091-2100 for the projections, or 2003-2012 for HIST and NoAA). A five-year running mean was applied to reduce noise in panel (b) and for the 20CRv2 data in panel (a).

result from Levy et al. (2013). The 2006-2100 linear warming trend due to declining AAs $\left(1.1^{\circ} \mathrm{C}\right.$ per $\left.95 \mathrm{yr}\right)$ is a little less than half the total warming trend in RCP45 $\left(2.3^{\circ} \mathrm{C}\right.$ per $95 \mathrm{yr}$ ). This is roughly in proportion to the TOA radiative forcing shown in Fig. 5, with aerosol ERF at the TOA slightly less than long-lived GHG ERF.

Another way to look at this is to note that RCP45A2005 shows slightly less warming by 2100 than RCP26 in CSIROMk3.6; in other words, without the extra warming effect of declining AAs, RCP45 would warm less than RCP26. The surface temperature response in RCP26 is also similar to the effect of declining aerosols in RCP45; this is broadly consistent with little forcing due to changes in greenhouse gases in RCP2.6 (Van Vuuren et al., 2011) and net aerosol changes that are similar to those in RCP4.5 by 2100 (Fig. 1c).

Another feature of RCP45A2005 is that it shows a noticeable flattening of the warming rate after about 2065, although it occurs later and is less pronounced than in the strongly mitigated RCP26 experiment. In both RCP45A2005 and RCP26, the timing of the flattening roughly corresponds to the flattening of the $\mathrm{CO}_{2}$ concentration increase (Van Vuuren et al., 2011) (their Fig. 9).

Figure $6 \mathrm{~b}$ compares changes in $T_{\mathrm{s}}$ for the $\mathrm{NH}$ and $\mathrm{SH}$. In RCP45A2005, the two hemispheres warm at similar rates $\left(1.2^{\circ} \mathrm{C}\right.$ per $\left.95 \mathrm{yr}\right)$. The $\mathrm{NH}$ is expected to warm more rapidly than the SH under strong long-lived GHG forcing due to its larger proportion of land, and deep ocean mixing in the SH. However, a weakening of northward heat transport by the Atlantic meridional overturning circulation (AMOC) can exert the dominant control on the inter-hemispheric warming difference under moderate warming scenarios (Feulner et al., 2013). Our simulations do exhibit a strong "warming hole" over the mid-latitude North Atlantic (not shown), indicative of a substantial weakening of the AMOC (Drijfhout et al., 2012). This is also shown by Weaver et al. (2012) (their Fig. 2), in which the projected AMOC in CSIRO-Mk3.6 weakens more rapidly than in most other CMIP5 models.

In contrast, the projected warming due to declining AAs (black curves in Fig. 6b) is almost twice as strong in the $\mathrm{NH}$ compared to the $\mathrm{SH}$. The linear trend (RCP45 minus $\mathrm{RCP} 45 \mathrm{~A} 2005)$ is $1.45^{\circ} \mathrm{C}$ per $95 \mathrm{yr}$ in the $\mathrm{NH}$ and $0.76^{\circ} \mathrm{C}$ per $95 \mathrm{yr}$ in the $\mathrm{SH}$. The ratio of warming between the hemispheres (1.9) is somewhat smaller than the inter-hemispheric forcing ratio (2.3). This difference may be due to a decrease of northward heat transport by the AMOC; historically increasing AAs have been shown to strengthen the AMOC in CSIRO-Mk3.6 (Collier et al., 2013), and the converse happens in response to declining AAs in RCP45 (figure not shown). Also, as we show in Sect. 4.2, the Hadley circulation responds to declining AAs in a way that transports heat from the $\mathrm{NH}$ to the $\mathrm{SH}$; this may also reduce the $\mathrm{NH}: \mathrm{SH}$ warming ratio.

\subsection{Precipitation changes}

Simulated global-mean precipitation (Fig. 7a) shows little change in 2005 relative to 1850; the larger hydrological sensitivity to aerosol forcing explains why this can occur, despite 
an increase in global-mean temperature (Kloster et al., 2010). In the model, substantial fluctuations during the historical period are associated with volcanic eruptions in the early 1880s, 1960s and 1990s (seen in NoAA as well as HIST) and strengthening aerosol effects between about 1960 and 1990. After the early 1990s, the model shows a positive precipitation trend in HIST, which continues into RCP45. Available evidence suggests that there is no clear long-term trend in global precipitation over land since 1950 (Balan Sarojini et al., 2012). Figure 7a includes a time series showing global-mean precipitation from version 2 of the 20th Century Reanalysis Project (20CRv2; Compo et al., 2011). Such reconstructions of historical precipitation are very uncertain, although Hwang et al. (2013) found that 20CR is broadly able to capture observed precipitation variations from the Global Precipitation Climatology Project during 1979-2010. The data from 20CR suggest large decadal fluctuations during much of the 20th century, and a gradual increase since about 1970. Since global-mean precipitation in the model starts to increase later than in the reconstruction, this discrepancy may suggest (for example) that the model does not accurately capture the trend in aerosol forcing in the late 20th century; in view of the uncertainties, careful analysis would be needed to clarify the interpretation.

In RCP45, global-mean precipitation increases by $0.16 \mathrm{~mm}$ per day in $95 \mathrm{yr}$ (about $5.6 \%$ of the model's climatological value). Of this, $63 \%$ can be attributed to the effects of declining aerosols, and the remainder to increasing GHGs. This can be compared to the simulations of Levy et al. (2013) using GFDL-CM3; they obtained a global-mean precipitation increase of $\sim 0.15 \mathrm{~mm}$ per day in RCP4.5, with more than half of this caused by declining aerosols.

For comparison, we again plot the curve from RCP26, in which the precipitation increase is slightly more than $0.1 \mathrm{~mm}$ per day in $95 \mathrm{yr}$, similar to the effect of declining aerosols in RCP45. As we found for global-mean $T_{\mathrm{S}}$ (Fig. 6), this suggests that changes in RCP26 (with weak long-lived GHG forcing) are dominated by aerosol forcing.

Hemispheric means are plotted in Fig. 7b. In HIST, the precipitation decline between 1960 and 1990 is mainly a NH phenomenon, as is the relatively strong precipitation increase in RCP45. The NH RCP4.5 precipitation increase is mostly due to declining aerosols (72\%). Especially remarkable is that the $95 \mathrm{yr}$ precipitation increase in RCP45 is roughly eight times as large in the $\mathrm{NH}(0.29 \mathrm{~mm}$ per day $)$ as in the SH ( $0.037 \mathrm{~mm}$ per day).

Why is the inter-hemispheric ratio in precipitation change in RCP45 much larger than the inter-hemispheric ratio in the TOA ERF (Fig. 5) or temperature change (Fig. 6)? In the $\mathrm{NH}$, precipitation increases are driven by the fast and slow responses to declining aerosols, as discussed in Sect. 3.2. To a lesser extent, aerosol ERF also changes in the SH (Fig. 5), so one might expect $\mathrm{SH}$ precipitation to also increase. However, the $95 \mathrm{yr}$ SH precipitation trend due to declining aerosols is essentially zero $(-0.00 \mathrm{~mm}$ per day). The reason is that hemispheric precipitation changes are dominated by the tropics, and there is a northward shift of tropical precipitation as a dynamical response to declining aerosols.

The zonally averaged circulation change associated with the northward precipitation shift can be represented by the trend in the meridional mass streamfunction $\Psi$, defined as (Buja, 1993)

$$
\Psi=\frac{2 \pi a \cos (\phi)}{g} \int_{P}^{P_{\mathrm{s}}} V \mathrm{~d} p,
$$

where $a$ is the radius of the Earth, $\phi$ is latitude, $g$ is the acceleration due to gravity, $V$ is the monthly mean meridional wind speed, $P$ is pressure and $P_{\mathrm{S}}$ is surface pressure. The trend in annual-mean $\Psi$ caused by declining AAs is shown in Fig. 8a. The anti-clockwise circulation trend (negative streamfunction change) implies anomalous ascent (subsidence) in the tropical NH (SH). This is of the opposite sign to the circulation change that has been found in simulations of the effects of historically increasing aerosols, both in CSIRO-Mk3.6 (Rotstayn et al., 2012) and other models (Williams et al., 2001; Ming and Ramaswamy, 2011). Note that energy transport by the Hadley circulation is in the direction of the upper branch (Chiang and Friedman, 2012; Hwang et al., 2013), so the anomalous circulation in Fig. 8a represents a net flux of energy from the NH to the SH.

The trend in tropical meridional circulation due to increasing greenhouse gases (Fig. 8b) is very different from the response to declining aerosols. Opposing circulation trends straddle the equator, representing increasing ascent in the equatorial zone, and compensating subsidence to the north and south. Increasing equatorial ascent in RCP45A2005 is a response to enhanced equatorial sea-surface warming, a common feature of climate projections forced by increasing greenhouse gases (Liu et al., 2005). This SST trend pattern is shown in Fig. 9 (red curve); as well as enhanced equatorial warming, there is also a weak inter-hemispheric warming gradient. SST trends induced by declining aerosols are markedly different (Fig. 9, blue curve). In the latter case, some equatorial enhancement is seen, but the dominant feature is stronger warming in the $\mathrm{NH}$ compared to the $\mathrm{SH}$, consistent with stronger aerosol forcing in the NH. This interhemispheric gradient in SST trends is reflected in the Hadley cell response to declining aerosols (Fig. 8a).

\section{Other CMIP5 models}

The above results suggest that projected 21 st century warming in RCP4.5 will tend to be larger in CMIP5 models that have stronger (more negative) aerosol ERF in the present climate, as the aerosol ERF declines during the 21st century. They also suggest that precipitation changes in RCP4.5 may be substantially constrained by aerosol changes. We test this 
a) RCP45: Trend from decreasing aerosols
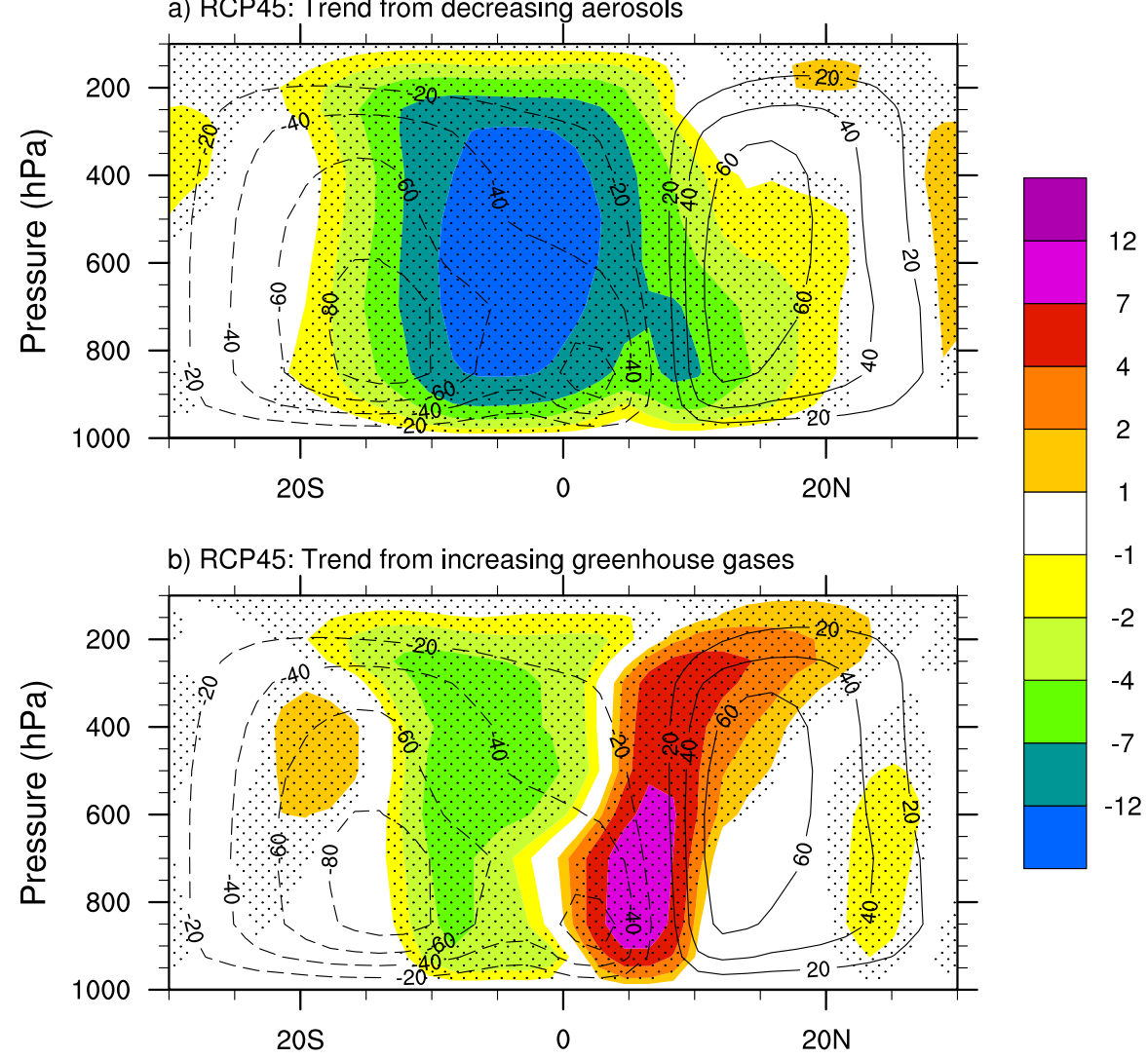

Fig. 8. 2006-2100 trends $\left(10^{9} \mathrm{~kg} \mathrm{~s}^{-1}\right.$ per century) in annual-mean meridional streamfunction (shaded) from (a) RCP45 minus RCP45A2005, and (b) RCP45A2005. Contours show the climatology from HIST, averaged over 1986-2005 $\left(10^{9} \mathrm{~kg} \mathrm{~s}^{-1}\right)$. Positive numbers denote clockwise circulation. Stippling denotes changes significant at $5 \%$, based on a two-sided $t$ test.

Zonal mean SST trends

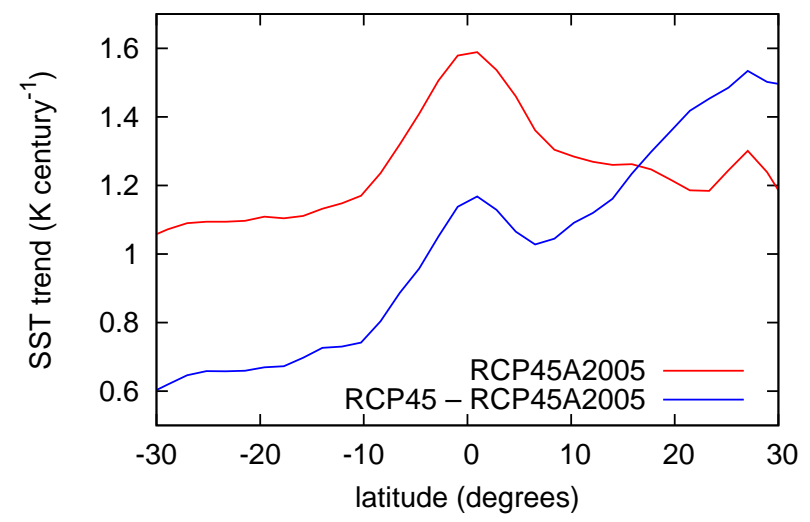

Fig. 9. 2006-2100 zonal-mean SST trends at low latitudes from RCP45A2005 (red curve) and RCP45 minus RCP45A2005 (blue curve).

hypothesis by plotting projected and historical changes in temperature and precipitation against (2000 relative to 1850 ) aerosol ERF for 13 CMIP5 models, which are listed in Table 1 . These are the models for which aerosol ERF (from
fixed-SST runs) was available for download at the time of writing, plus the ACCESS1.0 and ACCESS1.3 models (Bi et al., 2013; Dix et al., 2013) and GISS-E2-R (Shindell et al., $2013 b$ ). Temperature and precipitation changes are calculated from the least-squares trend, multiplied by the time period.

Aerosol ERF in 2100 is not available for the other CMIP5 models, so we use the historical change in aerosol ERF as a proxy for the future change in aerosol ERF (with signs reversed). This approach is based on the tacit assumption that aerosol ERF returns to roughly 19th century values by 2100 , as it does in CSIRO-Mk3.6, but the extent to which this is true will vary among the models.

Of particular interest in this respect is the role of nitrate aerosol. Few CMIP5 models include nitrate aerosol, and only one of the models we consider (GISS-E2-R) treats nitrate (Shindell et al., 2013b). Nitrate is expected to reduce the effect of declining aerosols, since emissions of ammonia from agriculture are assumed to increase in the RCPs (Van Vuuren et al., 2011; Bellouin et al., 2011; Lamarque et al., 2011). However, these increases are smaller in RCP4.5 than the other RCPs (Bellouin et al., 2011) (their Fig. 1). 
Table 1. Details of models used in Fig. 10 and subsequent figures.

\begin{tabular}{|c|c|c|c|c|}
\hline Model & Institution & Indirect effects ${ }^{1}$ & Runs $^{2}$ & References \\
\hline ACCESS $1.0^{3}$ & $\begin{array}{l}\text { CSIRO (Commonwealth Scientific and } \\
\text { Industrial Research Organisation) and } \\
\text { Bureau of Meteorology, Australia }\end{array}$ & 2 & $2 / 1$ & Bi et al. (2013); Dix et al. (2013) \\
\hline ACCESS $1.3^{3}$ & CSIRO and Bureau of Meteorology, Australia & 2 & $3 / 1$ & Bi et al. (2013); Dix et al. (2013) \\
\hline BCC-CSM1.1 & $\begin{array}{l}\text { Beijing Climate Center, China Meteorological } \\
\text { Administration }\end{array}$ & 0 & $3 / 1$ & Xin et al. $(2013 a, b)$ \\
\hline CanESM2 & $\begin{array}{l}\text { Canadian Centre for Climate Modelling and } \\
\text { Analysis }\end{array}$ & 1 & $5 / 5$ & von Salzen et al. (2013) \\
\hline CSIRO-Mk3.6 & $\begin{array}{l}\text { CSIRO with the Queensland Climate Change } \\
\text { Centre of Excellence }\end{array}$ & 2 & $10 / 10$ & Rotstayn et al. (2012); Jeffrey et al. (2013) \\
\hline GFDL-CM3 & Geophysical Fluid Dynamics Laboratory & 2 & $5 / 1$ & Levy et al. (2013) \\
\hline GISS-E2-R ${ }^{4}$ & NASA Goddard Institute for Space Studies & 1 & $6 / 6$ & Shindell et al. (2013b) \\
\hline HadGEM2-AO ${ }^{5}$ & Met Office Hadley Centre & 2 & $1 / 1$ & Jones et al. (2011); Martin et al. (2011) \\
\hline HadGEM2-ES ${ }^{5}$ & Met Office Hadley Centre & 2 & $5 / 4$ & Jones et al. (2011); Martin et al. (2011) \\
\hline IPSL-CM5A-LR & Institut Pierre-Simon Laplace & 1 & $6 / 4$ & Dufresne et al. (2013); Szopa et al. (2013) \\
\hline MIROC5 & $\begin{array}{l}\text { Atmosphere and Ocean Research Institute, } \\
\text { National Institute for Environmental Studies, } \\
\text { and Japan Agency for Marine-Earth Science } \\
\text { and Technology }\end{array}$ & 3 & $5 / 3$ & Watanabe et al. (2010); Komuro et al. (2012) \\
\hline MRI-CGCM3 & Meteorological Research Institute & 3 & $3 / 1$ & Yukimoto et al. (2012) \\
\hline NorESM1-M & Norwegian Climate Centre & 2 & $3 / 1$ & Iversen et al. (2013); Kirkevåg et al. (2013) \\
\hline
\end{tabular}

Bellouin et al. (2011) calculated nitrate forcing for the four RCPs in a version of HadGEM2-ES. Note that nitrate was not treated in the HadGEM2-ES CMIP5 runs. In RCP4.5, they found that ammonium nitrate exerted (direct plus first indirect) forcing of $-0.2 \mathrm{~W} \mathrm{~m}^{-2}$ in 2090 relative to 2000 , somewhat less than the forcing they obtained for the other RCPs $\left(-0.3\right.$ to $\left.-0.5 \mathrm{~W} \mathrm{~m}^{-2}\right)$. Negative forcing was obtained in $\mathrm{RCP} 4.5$, despite relatively flat emissions of ammonia, due to competition between nitrate and sulfate precursors for a limited supply of ammonia.

Aside from nitrate, the relative roles of sulfate and carbonaceous aerosols are also important. We noted in Sect. 3.2 that CSIRO-Mk3.6 has a substantial negative ERF of $-0.3 \mathrm{~W} \mathrm{~m}^{-2}$ due to carbonaceous aerosol (for 2000 relative to 1850). Several of the groups listed in Table 1 submitted fixed-SST runs that enable calculation of the 2000 minus 1850 ERF for sulfate aerosol; for models that exclude nitrate, the difference between total aerosol ERF and sulfate ERF gives the carbonaceous-aerosol ERF (assuming linearity). There is wide disagreement among the models, e.g. MRI-CGCM3 has a relatively large negative ERF for carbonaceous aerosol $\left(-0.6 \mathrm{~W} \mathrm{~m}^{-2}\right)$, whereas some models (such as CanESM2, HadGEM2 and IPSL-CM5A-LR) have carbonaceous-aerosol ERF that is close to zero. Since the negative component of carbonaceous-aerosol ERF is likely to be mostly related to $\mathrm{OA}$ rather than $\mathrm{BC}$, and $\mathrm{OA}$ emissions in RCP4.5 return to 19th century levels sooner than $\mathrm{SO}_{2}$ or BC emissions (Fig. 1a), these differences between models are likely to contribute to the scatter seen in the following figures.

\subsection{Global-mean temperature}

In Fig. 10 we plot projected (2006-2100) and historical (1850-2005) changes in global-mean surface air temperature against aerosol ERF. The average aerosol ERF for the 13 models is $-1.15 \mathrm{~W} \mathrm{~m}^{-2}$; the range is -0.38 to $-1.62 \mathrm{~W} \mathrm{~m}^{-2}$, or -0.76 to $-1.62 \mathrm{~W} \mathrm{~m}^{-2}$ for models that include indirect aerosol effects. Models that include the second indirect effect tend to have more negative global-mean aerosol ERF; see Table 1. Although the magnitude (and possibly even the sign) of this effect in the real world is highly uncertain (e.g., Sandu et al., 2008), a decrease of precipitation efficiency with increasing aerosol concentration generally leads to an increase of cloud liquid water path in GCMs. This effect may be systematically overpredicted in GCMs, because they are unable to resolve other associated processes. For example, smaller cloud droplets in clouds affected by increased aerosol concentration may evaporate more readily, increasing the entrainment of dry air and thereby reducing 
a) RCP4.5

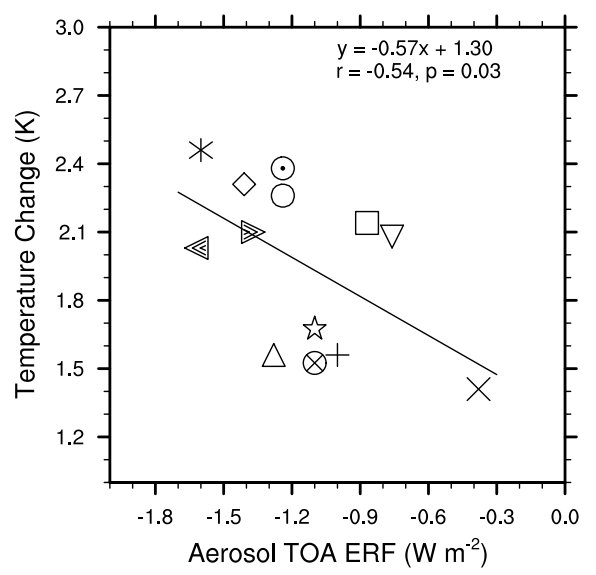

b) HIST

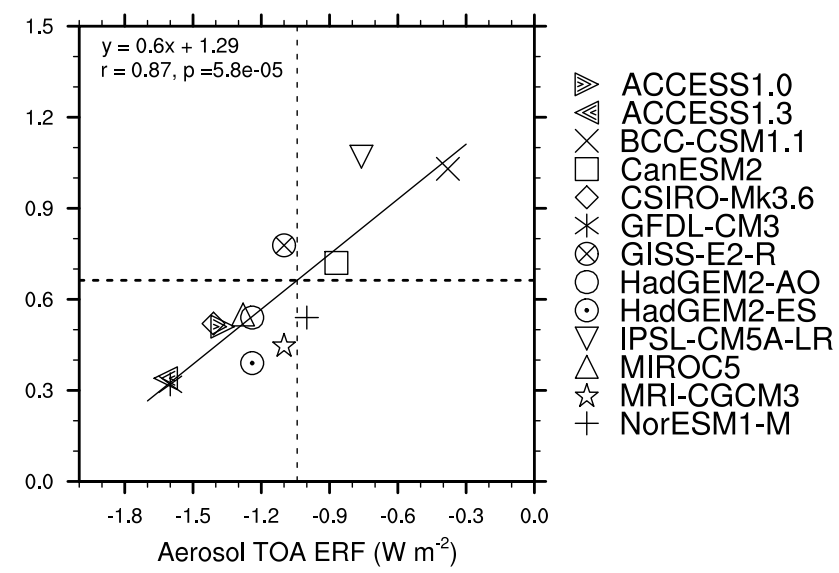

Fig. 10. Changes in global-mean surface-air temperature from CMIP5 models plotted against (2000 relative to 1850) global-mean aerosol ERF diagnosed from fixed-SST simulations: (a) RCP4.5 (2006-2100), (b) historical simulations (1850-2005). CMIP5 models are listed in Table 1. Temperature changes are calculated from least-squares trends. Also shown in each panel are the regression line, the equation for the regression line, the correlation and the level of significance. The dashed horizontal line in (b) shows the observed 1850-2005 warming from HadCRUT4, and the dashed vertical line shows the "top-down" estimate of aerosol ERF implied by the intersection of the horizontal line with the regression line.

cloud lifetime (Jiang et al., 2006). Such interactions are usually not resolved by the cloud schemes in current GCMs. Note that two models (MRI-CGCM3 and MIROC5) also include aerosol effects on ice clouds, though it is unclear how this influences the aerosol ERF in these models.

Figure 10a shows a correlation $(r)$ of -0.54 between aerosol ERF and projected warming in RCP4.5, with a level of significance $(p)$ of 0.03 . For comparison, panel b shows the correlation for the historical period, which is markedly stronger $(r=0.87)$. Aerosol ERF accounts for $76 \%$ of the inter-model variance in simulated historical global-mean warming. The stronger correlation in the historical period presumably occurs because the net forcing is much weaker than in RCP4.5, so climate feedbacks are much weaker. Also, as noted above, we use historical aerosol ERF as a proxy for future aerosol ERF, and this probably contributes to the scatter seen in Fig. 10a.

Although the main focus of this paper is on RCP4.5, the good correlation between aerosol ERF and simulated historical warming suggests that this might provide a useful "topdown" estimate of aerosol ERF. The observed 1850-2005 surface warming from HadCRUT4 (Morice et al., 2012) is $0.66^{\circ} \mathrm{C}$, shown as the dashed horizontal line in Fig. $10 \mathrm{~b}$. The intersection of the regression line with the observed temperature change implies an estimated aerosol ERF of $-1.04 \mathrm{~W} \mathrm{~m}^{-2}$, if this subset of CMIP5 models has no systematic bias in equilibrium climate sensitivity or ocean heat uptake.

Using a similar approach with several CMIP5 models, Shindell et al. (2013a) suggested that aerosol ERF of about -0.8 to $-1.5 \mathrm{~W} \mathrm{~m}^{-2}$ is consistent with the observed historical warming; their uncertainty estimate incorporated the use of observed temperature change from two different data sets and different rates of warming in individual ensemble members in the CMIP5 models. A larger estimate of observed temperature change in the GISS data set (Hansen et al., 2006) than in HadCRUT3 (Brohan et al., 2006) suggested a slightly less negative value for aerosol ERF based on the GISS data set.

The full uncertainty range for such top-down calculations may be even larger than the range given by Shindell et al. (2013a), due to uncertainties in observed temperature changes, climate sensitivity and ocean heat uptake. For example, Hansen et al. (2011) argued that their GCM (and many others) have excessive heat uptake by the deep ocean; after adjusting the temporal response function to account for this, they estimated aerosol forcing as $-1.6 \pm 0.3 \mathrm{~W} \mathrm{~m}^{-2}$ by comparison with observational records. On the other hand, Libardoni and Forest (2011) obtained a much smaller aerosol forcing $\left(-0.19\right.$ to $\left.-0.83 \mathrm{~W} \mathrm{~m}^{-2}\right)$, with substantial sensitivity to the choice of observational data sets. A complementary approach uses satellite retrievals to constrain model calculations; for example, Quaas et al. (2009) estimated aerosol $\mathrm{ERF}$ as $-1.2 \pm 0.2 \mathrm{~W} \mathrm{~m}^{-2}$.

Recently, IPCC (2013) provided a best estimate of aerosol ERF (for 2011 relative to 1750 ) of $-0.9 \mathrm{~W} \mathrm{~m}^{-2}$, which is smaller in magnitude than the forcing estimate from the 2007 report. However, the uncertainty range remains large $(-0.1$ to $-1.9 \mathrm{~W} \mathrm{~m}^{-2}$ ).

Although the evidence presented here is mixed, it seems more likely than not that our model's aerosol ERF at the TOA $\left(-1.4 \mathrm{~W} \mathrm{~m}^{-2}\right.$ in 2000) is too strong. On the other hand, CSIRO-Mk3.6 tends to underestimate atmospheric aerosol 
a) RCP4.5

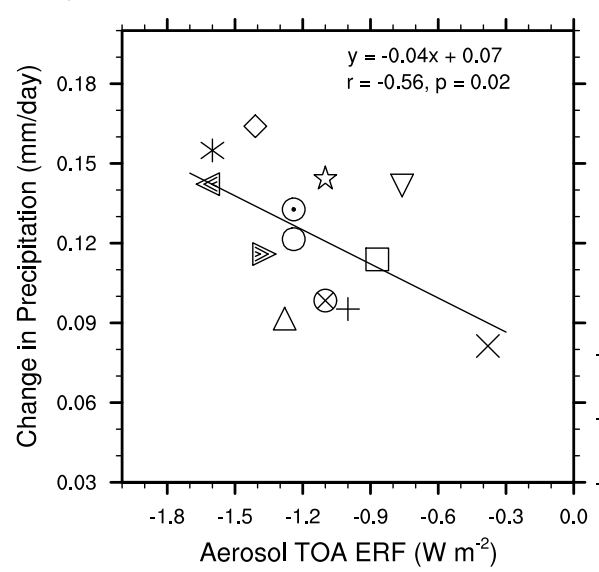

b) HIST

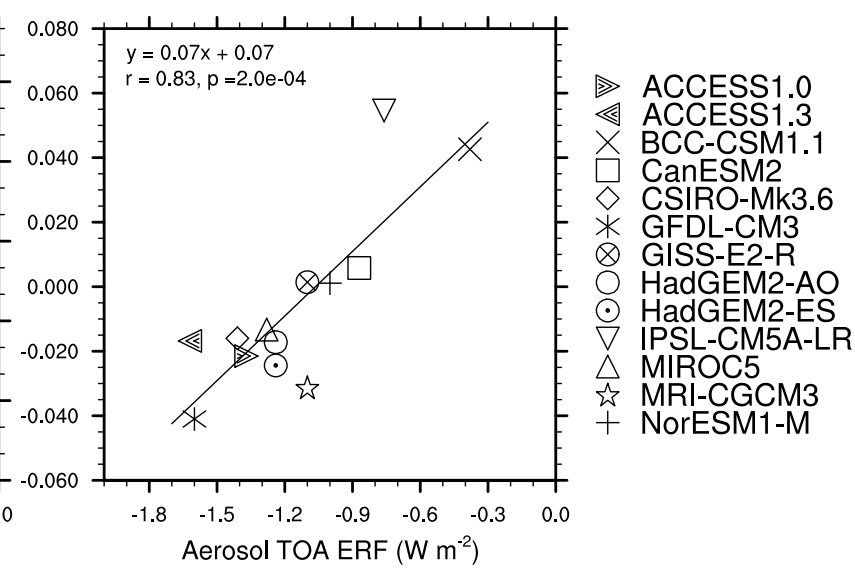

Fig. 11. Changes in global-mean precipitation from CMIP5 models plotted against (2000 relative to 1850) global-mean aerosol ERF diagnosed from fixed-SST simulations: (a) RCP4.5 (2006-2100), (b) historical simulations (1850-2005). Precipitation changes are calculated from least-squares trends. Also shown in each panel are the regression line, the equation for the regression line, the correlation and the level of significance.

absorption of shortwave radiation, in common with other models (Shindell et al., 2013a). This is likely due to a combination of underestimated BC concentrations and underestimated absorption per unit mass (Koch et al., 2009).

\subsection{Global-mean precipitation}

Are changes in global precipitation similarly constrained by TOA aerosol ERF in these models? Figure 11 shows that for both RCP4.5 $(r=-0.56)$ and the historical runs $(r=0.83)$, the correlation is comparable to what we found for temperature. In the historical runs, models with relatively strong aerosol ERF (less than about $-1.1 \mathrm{~W} \mathrm{~m}^{-2}$ ) tend to have negative precipitation changes, despite increasing global-mean $T_{\mathrm{S}}$. This reflects the larger hydrological sensitivity for aerosol forcing compared to GHG forcing (Sect. 3.2).

The projected precipitation change for GISS-E2-R is plotted below the regression line in Fig. 11a. A similar result was seen for temperature in Fig. 10a. In other words, its response is relatively subdued in RCP4.5, consistent with its inclusion of nitrate. However, it does not appear as an outlier relative to the other models, which suggests that inclusion of nitrate may not be a dominant factor that modulates the aerosolinduced response in RCP4.5. As indicated by Bellouin et al. (2011), nitrate is likely to be relatively more important in the other RCPs, in which it can substantially reduce the impact of decreasing $\mathrm{SO}_{2}$ emissions.

\subsection{Hemispheric means}

In Fig. 12 we plot hemispheric-mean near-surface temperature changes against hemispheric-mean aerosol ERF. The average aerosol ERF across 12 models is $-1.73 \mathrm{~W} \mathrm{~m}^{-2}$ in the $\mathrm{NH}$ and $-0.56 \mathrm{~W} \mathrm{~m}^{-2}$ in the SH. The correlations are bet- ter in the $\mathrm{NH}$ than the $\mathrm{SH}$, due to stronger aerosol forcing in the $\mathrm{NH}$, though they are still significant in the $\mathrm{SH}$. As seen for the global means, the correlations are also better in the historical experiments than in RCP4.5. All the models have larger warming in the $\mathrm{NH}$ than the $\mathrm{SH}$ in RCP4.5. This is not the case for several of the historical experiments, in which increasing aerosols tend to cool the $\mathrm{NH}$ relative to the $\mathrm{SH}$.

Some of the scatter seen in RCP4.5 (panels a and c) is due to the fact that aerosol ERF in 2100 is not the same as in 1850. For example, the smallest NH warming in RCP4.5 is obtained from GISS-E2-R, which probably reflects the influence of nitrate in that model.

Top-down estimates of aerosol ERF are again shown by the vertical dashed lines, namely $-1.60 \mathrm{~W} \mathrm{~m}^{-2}$ in the $\mathrm{NH}$ and $-0.42 \mathrm{~W} \mathrm{~m}^{-2}$ in the SH. These are likely to be more uncertain than the global-mean estimates in Sect. 5.1.

Similar hemispheric scatter plots are shown for precipitation in Fig. 13. As expected, the correlation of both historical and projected precipitation changes with aerosol ERF is stronger in the historical experiments than in RCP4.5, and stronger in the $\mathrm{NH}$ than the $\mathrm{SH}$. In the historical experiments, correlations are highly significant in the $\mathrm{NH}$, and in the $\mathrm{SH}$ the correlation is significant at $5 \%$. Although the correlation in the SH is weak in RCP4.5 (panel c), it is worth noting that the regression line has a reversed slope compared to that in the NH (panel a). This suggests that, at least in some of the models, the $\mathrm{SH}$ precipitation response is partly controlled by compensating tropical subsidence relative to the $\mathrm{NH}$ (as we saw in CSIRO-Mk3.6).

Such dynamic effects may strengthen the relationship between aerosol ERF and projected precipitation changes in the $\mathrm{NH}$, and weaken it in the SH. One way to see this is to compare the regression slopes in RCP4.5 between temperature 
a) $\mathrm{NH} \mathrm{RCP4.5}$

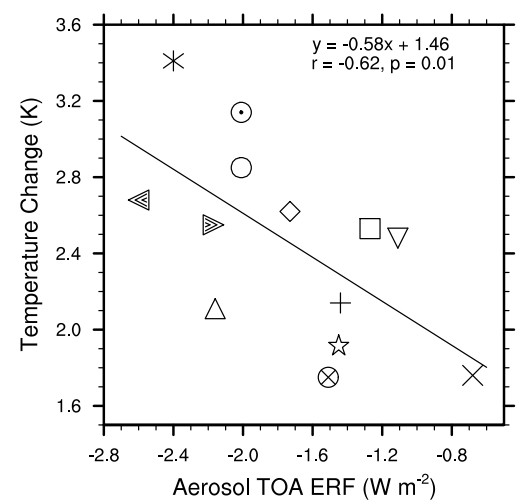

b) $\mathrm{NH} \mathrm{HIST}$

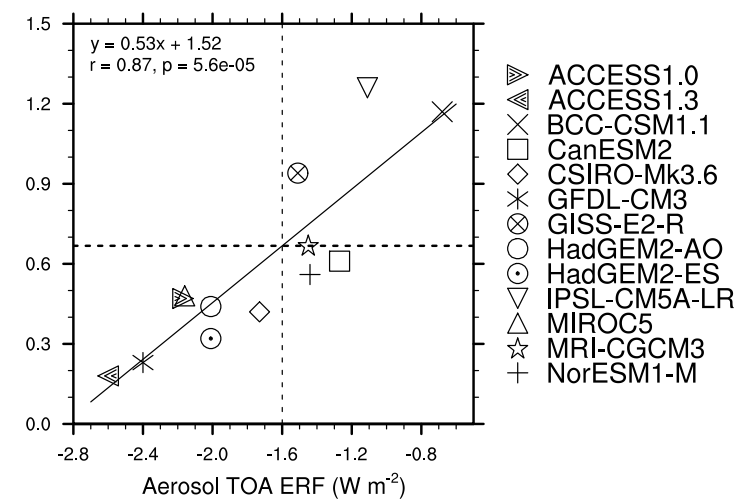

c) SH RCP4.5

d) SH HIST
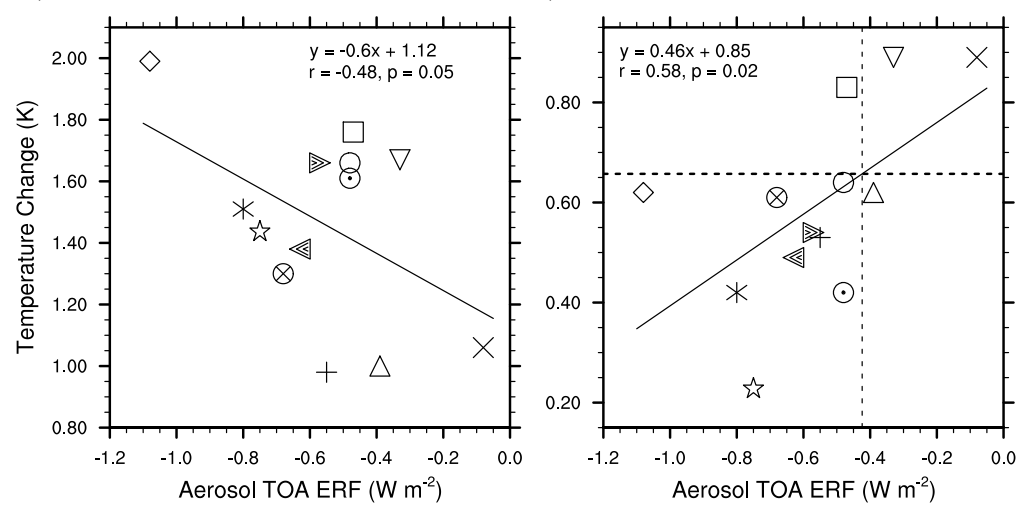

Fig. 12. Changes in hemispheric-mean surface-air temperature from CMIP5 models plotted against (2000 relative to 1850) hemisphericmean aerosol ERF diagnosed from fixed-SST simulations: (a) NH RCP4.5, (b) NH historical simulations, (c) SH RCP4.5, (d) SH historical simulations. Also shown in each panel are the regression line, the equation for the regression line, the correlation and the level of significance. The dashed horizontal lines in panels (b) and (d) show the observed 1850-2005 hemispheric-mean warming from HadCRUT4, and the dashed vertical lines show the "top-down" estimate of aerosol ERF implied by the intersection of the horizontal lines with the regression lines.

and aerosol ERF (Figs. 10 and 12) with those between precipitation and aerosol ERF (Figs. 11 and 13). For temperature, these are similar in the global mean, the $\mathrm{NH}$ and the SH $\left(-0.57,-0.58\right.$ and $-0.60 \mathrm{~K}\left(\mathrm{Wm}^{-2}\right)^{-1}$, respectively). For precipitation, there is a large difference between the regression slope based on global means $(-0.04 \mathrm{~mm}$ per day $\left.\left(\mathrm{W} \mathrm{m}^{-2}\right)^{-1}\right)$ and the slopes in the $\mathrm{NH}$ and $\mathrm{SH}(-0.07$ and $0.02 \mathrm{~mm}$ per day $\left(\mathrm{W} \mathrm{m}^{-2}\right)^{-1}$, respectively).

This point is further reinforced by plotting the regression line that relates global-mean precipitation changes to aerosol ERF (from Fig. 11a) on the same axes as the projected changes in hemispheric precipitation (the dashed lines in Fig. 13a and c). The dashed lines represent the expected changes in projected hemispheric precipitation if the global relationship between aerosol ERF and precipitation holds on hemispheric scales. In the $\mathrm{NH}$, all except two models have precipitation changes that are larger than expected from this relationship, whereas in the $\mathrm{SH}$ all models except one have precipitation changes that are smaller than expected. Over- all, 10 of 13 models lie above the dashed curve in the $\mathrm{NH}$ and below the dashed curve in the SH.

Taken together, these results suggest that most of the models show an inter-hemispheric dynamic response to declining AAs; this dynamic effect tends to increase precipitation in the $\mathrm{NH}$, and decrease it in the $\mathrm{SH}$, relative to the expected change from hemispheric-mean aerosol ERF. It should be noted that these arguments are quite simplified; for example, we have not considered the role of aerosol atmospheric ERF, which may increase the precipitation response in models with stronger atmospheric heating by black carbon (Sect. 3.2). A more rigorous assessment would probably require analysis of the circulation trends in the various models.

\section{Summary and conclusions}

We focused on the medium-low RCP4.5 scenario, and assessed simulated global and hemispheric-scale effects of declining aerosols in CSIRO-Mk3.6. We also compared aspects 


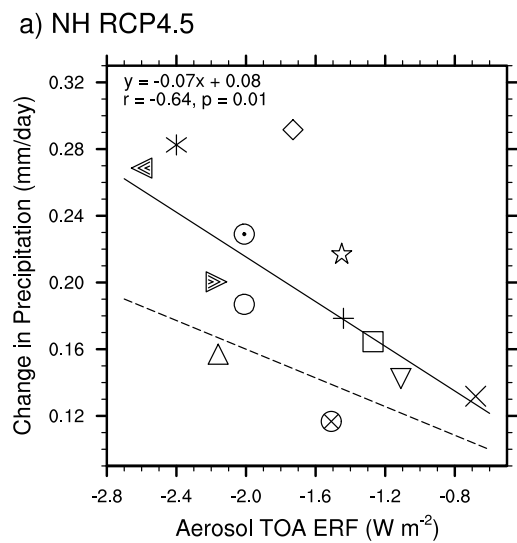

b) NH HIST
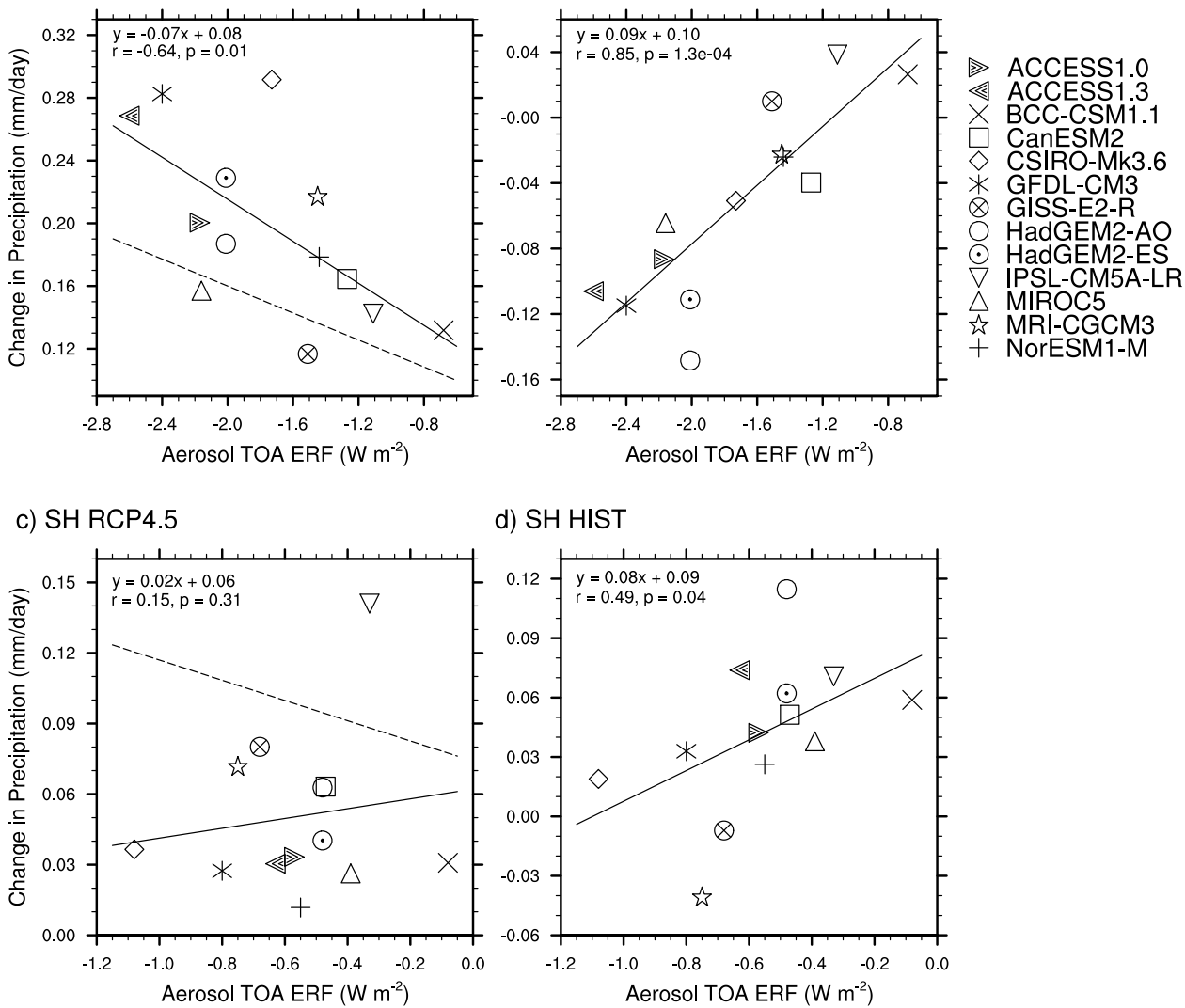

d) SH HIST

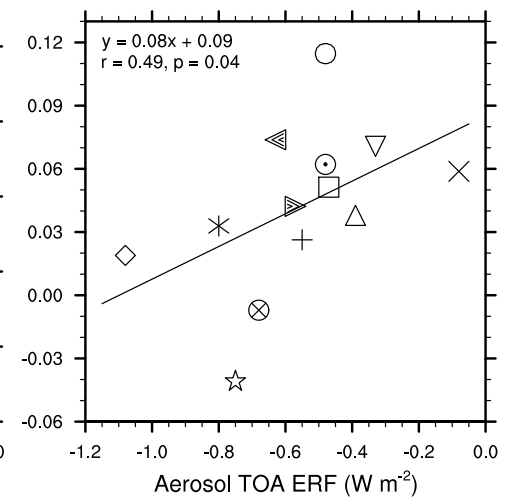

Fig. 13. Changes in hemispheric-mean precipitation from CMIP5 models plotted against (2000 relative to 1850) hemispheric-mean aerosol ERF diagnosed from fixed-SST simulations: (a) NH RCP4.5, (b) NH historical simulations, (c) SH RCP4.5, (d) SH historical simulations. Also shown in each panel are the regression line, the equation for the regression line, the correlation and the level of significance. The dashed lines in panels (a) and (c) reproduce the regression line from Fig. 11a, namely, the relation between projected changes in global-mean precipitation and global-mean aerosol ERF.

of our results with other CMIP5 models for which estimates of aerosol ERF were available. Our simulations were forced by changes in emissions of sulfur dioxide, organic aerosol and black carbon from anthropogenic sources and biomass burning, and changing prescribed concentrations of longlived GHGs and ozone.

We calculated the aerosol effective radiative forcing (ERF) using a series of atmospheric simulations with prescribed sea-surface temperatures, and compared the aerosol ERF with similar calculations of the ERF from increasing longlived GHGs. We then compared two 10-member ensembles that used the coupled atmosphere-ocean version of the model. One (RCP45) was forced by the usual RCP4.5 during 2006-2100; the other (RCP45A2005) used identical forcing, except that emissions of anthropogenic aerosols and precursors were fixed at 2005 levels. Assuming linearity, the effects of declining aerosols were diagnosed from RCP45 minus RCP45A2005, while RCP45A2005 represented the effects of changes in GHGs. Since changes in tropospheric ozone are relatively small in RCP4.5, and our focus was on global and hemispheric-mean trends, to a good approximation RCP45A2005 represented the effects of increasing longlived GHGs in RCP4.5.

Relative to 1850, global-mean aerosol ERF at the top of the atmosphere was $-1.40 \mathrm{~W} \mathrm{~m}^{-2}$ in 2000 and $-1.47 \mathrm{~W} \mathrm{~m}^{-2}$ in 2005. Relative to 2005 , aerosol ERF was $1.46 \mathrm{Wm}^{-2}$ in 2100 , i.e., it approximately returned to 1850 levels. In our runs, increasing long-lived GHGs and declining aerosols exerted a positive ERF of similar magnitude at the top of the atmosphere between 2005 and 2100, but they had opposing effects on radiative heating within the atmosphere. Increasing GHGs exerted positive ERF in the atmosphere $\left(+1.00 \mathrm{~W} \mathrm{~m}^{-2}\right)$, whereas declining aerosols exerted negative $\operatorname{ERF}\left(-0.86 \mathrm{~W} \mathrm{~m}^{-2}\right)$ due to reduced absorption of shortwave radiation by black carbon. This difference was also reflected in the corresponding ERF at the surface $\left(+2.32 \mathrm{~W} \mathrm{~m}^{-2}\right.$ for declining aerosols, versus $+0.54 \mathrm{~W} \mathrm{~m}^{-2}$ for increasing longlived GHGs).

The global-mean 2006-2100 projected surface warming in RCP45 was $2.3{ }^{\circ} \mathrm{C}$, of which almost half $\left(1.1^{\circ} \mathrm{C}\right)$ was caused 
by declining aerosols. The warming due to declining aerosols was almost twice as strong in the $\mathrm{NH}$ as in the $\mathrm{SH}$, whereas that due to increasing GHGs was similar in the two hemispheres.

Comparing declining aerosols with increasing GHGs, different radiative forcing at the surface and in the atmosphere had important implications for the hydrological cycle. For precipitation changes, the simulated effects of declining aerosols were substantially larger than those of increasing GHGs. Globally, $63 \%$ of the projected 2006-2100 precipitation increase of $0.16 \mathrm{~mm}$ per day in RCP45 was caused by declining aerosols, and in the $\mathrm{NH}$ the corresponding proportion was even higher $(72 \%)$. The ratio of $\mathrm{NH} / \mathrm{SH}$ precipitation change in RCP45 was much larger than suggested by the inter-hemispheric ratio in ERF. We showed that this was likely associated with changes in the Hadley circulation induced by declining aerosols; increasing ascent (subsidence) in the tropics of the $\mathrm{NH}(\mathrm{SH})$ increased the ratio of $\mathrm{NH} / \mathrm{SH}$ precipitation change.

Our global-mean results are similar to those of Levy et al. (2013), who described an analogous experiment with the GFDL-CM3 model. They obtained additional global-mean warming due to declining aerosols of approximately $1{ }^{\circ} \mathrm{C}$ during 2006-2100 (compared to $1.1^{\circ} \mathrm{C}$ in CSIRO-Mk3.6). For precipitation, Levy et al. (2013) found that declining aerosols caused an increase of approximately $0.1 \mathrm{~mm}$ per day, which is similar to the result from CSIRO-Mk3.6 ( $0.10 \mathrm{~mm}$ per day).

The above findings in a model with relatively strong present-day aerosol ERF raised interesting questions about similar effects in other CMIP5 models. Using data from 13 CMIP5 models (for which aerosol ERF could be calculated from fixed-SST experiments), we found that projected global-mean surface warming in RCP4.5 tends to be larger in the models that have more negative aerosol ERF in the present climate $(r=-0.54, p=0.03)$. A similar correlation was found for global-mean precipitation changes $(r=-0.56, p=0.02)$.

Correlations between global-mean aerosol ERF and historical (1850-2005) simulated changes were much stronger $(r=0.87$ for surface temperature and $r=0.83$ for precipitation). We attributed this to weaker net forcing in the historical experiments than in RCP4.5. These results imply that aerosol ERF is the primary determinant of inter-model variations in simulated historical changes in global-mean surface temperature and precipitation. We took advantage of the strong correlation for surface temperature to calculate a simple top-down estimate of global-mean aerosol ERF for the year $2000\left(-1.04 \mathrm{~W} \mathrm{~m}^{-2}\right.$, assuming that these models have no systematic bias in equilibrium climate sensitivity or ocean heat uptake). As discussed in Sect. 5.1, there is large uncertainty associated with this estimate.

Considering hemispheric-mean changes in surface temperature and precipitation, correlations with aerosol ERF were stronger in the $\mathrm{NH}$ than the SH. Even in the SH, signif- icant correlations were obtained between hemispheric-mean aerosol ERF and simulated surface temperature and precipitation changes. A clear exception was projected precipitation change in the SH, which suggested a degree of dynamical control from the Hadley circulation in the $\mathrm{NH}$.

Aerosol ERF in 2100 was not available for the other CMIP5 models, and our approach was based on the tacit assumption that aerosol ERF returns to roughly 19th century values by 2100 in these models (as it did in CSIRO-Mk3.6). The extent to which this is true will vary among the models. For example, it may not be a good assumption for GISS-E2$\mathrm{R}$, which is the only model we considered that treats nitrate aerosol. Nitrate is expected to offset the effects of declines in other aerosol species, since emissions of ammonia from agriculture are projected to increase in the RCPs (though less so in RCP4.5 than in the other RCPs).

Our results suggest that the effects of declining aerosols in some respects resemble the effects of increasing GHGs, and in other respects are quite distinct. Thus, it is only partly accurate to think of declining aerosols as "unmasking" global warming, as asked in the title of this paper. Both forcings increase global-mean temperature, but aerosols act more strongly in the $\mathrm{NH}$ than the $\mathrm{SH}$. Aside from stronger effects on surface temperature in the $\mathrm{NH}$ than the $\mathrm{SH}$ from aerosols, this also implies a different response of atmospheric circulation for declining aerosols and increasing GHGs, which we showed for the Hadley circulation in Fig. 8. Recent work suggests that such changes in the Hadley circulation can affect the mid-latitude jet streams, especially in the SH in austral winter (Ceppi et al., 2013); in view of the distance of the SH eddy-driven jet from the location of strongest aerosol forcing in the $\mathrm{NH}$, this is an intriguing topic for further research.

Further, the combination of positive TOA ERF and negative atmospheric ERF from declining aerosols implies a substantially stronger response of global precipitation than from increasing long-lived GHGs. This has previously been noted in equilibrium climate simulations by Kloster et al. (2010). Although the larger hydrological sensitivity of aerosol forcing compared to long-lived GHGs has been discussed in a number of studies, it is perhaps more noticeable in these projections than in the more familiar case of historically increasing aerosols, because here both forcing agents contribute to global warming and increasing precipitation.

This paper has focused on aerosols, which contribute the largest uncertainty to radiative forcing. This compounds the uncertainty caused by climate feedbacks, especially those related to clouds (Dufresne and Bony, 2008). However, the effective radiative forcing due to increasing $\mathrm{CO}_{2}$ also shows substantial variation among CMIP5 models, due to different rapid adjustments of the atmosphere and land surface (Andrews et al., 2012); this would also contribute to the scatter seen in Sect. 5.

Our results suggest that, in the medium-low RCP4.5 scenario, the response of CMIP5 models is substantially modulated by their present-day aerosol ERF. The relative 
importance of declining aerosols will presumably be smaller in RCP8.5, but larger in RCP2.6. Systematic efforts are needed to better quantify the role of declining aerosols in climate projections.

Acknowledgements. We thank Peter Vohralik and the anonymous referees for their comments on the manuscript, and Arnold Sullivan, Julie Noonan and Peter Vohralik for their work on the ACCESS forcing runs. L. Rotstayn and M. Collier were partly supported by the Australian Climate Change Science Program. We acknowledge the World Climate Research Programme's Working Group on Coupled Modelling, which is responsible for CMIP, and we thank the climate modeling groups (listed in Table 1 of this paper) for producing and making available their model output. For CMIP the US Department of Energy's Program for Climate Model Diagnosis and Intercomparison provides coordinating support and led development of software infrastructure in partnership with the Global Organization for Earth System Science Portals.

Edited by: D. Shindell

\section{References}

Ackerley, D., Booth, B. B. B., Knight, S. H. E., Highwood, E. J., Frame, D. J., Allen, M. R., and Rowell, D. P.: Sensitivity of 20th century Sahel rainfall to sulfate aerosol and $\mathrm{CO}_{2}$ forcing, J. Climate, 24, 4999-5014, doi:10.1175/JCLI-D-11-00019.1, 2011.

Allan, R. P., Liu, C., Zahn, M., Lavers, D. A., Koukouvagias, E., and Bodas-Salcedo, A.: Physically consistent responses of the global atmospheric hydrological cycle in models and observations, Surv. Geophys., 34, 1-20, doi:10.1007/s10712-012-9213z, 2013.

Allen, M. R. and Ingram, W. J.: Constraints on future changes in climate and the hydrologic cycle, Nature, 419, 224-232, 2002.

Andreae, M. O. and Rosenfeld, D.: Aerosol-cloudprecipitation interactions. Part 1 . The nature and sources of cloud-active aerosols, Earth-Sci. Rev., 89, 13-41, doi:10.1016/j.earscirev.2008.03.001, 2008.

Andrews, T., Forster, P. M., and Gregory, J. M.: A surface energy perspective on climate change, J. Climate, 22, 2557-2570, doi:10.1175/2008JCLI2759.1, 2009.

Andrews, T., Forster, P. M., Boucher, O., Bellouin, N., and Jones, A.: Precipitation, radiative forcing and global temperature change, Geophys. Res. Lett., 37, L14701, doi:10.1029/2010GL043991, 2010.

Andrews, T., Gregory, J. M., Webb, M. J., and Taylor, K. E.: Precipitation, radiative forcing and global temperature change, Geophys. Res. Lett., 37, L09712, doi:10.1029/2012GL051607, 2012.

Arblaster, J. M., Meehl, G. A., and Karoly, D. J.: Future climate change in the Southern Hemisphere: competing effects of ozone and greenhouse gases, Geophys. Res. Lett., 38, L02701, doi:10.1029/2010GL045384, 2011.

Balan Sarojini, B., Stott, P. A., Black, E., and Polson, D.: Fingerprints of changes in annual and seasonal precipitation from CMIP5 models over land and ocean, Geophys. Res. Lett., 39, L21706, doi:10.1029/2012GL053373, 2012.

Bellouin, N., Rae, J., Jones, A., Johnson, C., Haywood, J., and Boucher, O.: Aerosol forcing in the Climate Model Intercom- parison Project (CMIP5) simulations by HadGEM2-ES and the role of ammonium nitrate, J. Geophys. Res., 116, D20206, doi:10.1029/2011JD016074, 2011.

Bi, D., Dix, M., Marsland, S. J., O’Farrell, S., Rashid, H., Uotila, P., Hirst, A. C., Kowalczyk, E., Golebiewski, M., Sullivan, A., Yan, H., Hannah, N., Franklin, C., Sun, Z., Vohralik, P., Watterson, I., Zhou, X., Fiedler, R., Collier, M., Ma, Y., Noonan, J., Stevens, L., Uhe, P., Zhu, H., Griffies, S. M., Hill, R., Harris, C., and Puri, K.: The ACCESS Coupled Model: Description, Control Climate and Evaluation, Aust. Meteorol. Oceanogr. J., 63, 41-64, 2013.

Bollasina, M. A., Ming, Y., and Ramaswamy, V.: Anthropogenic aerosols and the weakening of the South Asian summer monsoon, Science, 334, 502-505, doi:10.1126/science.1204994, 2011.

Booth, B. B. B., Dunstone, N. J., Halloran, P. R., Andrews, T., and Bellouin, N.: Aerosols implicated as a prime driver of twentiethcentury North Atlantic climate variability, Nature, 484, 228-232, doi:10.1038/nature10946, 2012.

Brohan, P., Kennedy, J. J., Harris, I., Tett, S. F. B., and Jones, P. D.: Uncertainty estimates in regional and global observed temperature changes: A new data set from 1850, J. Geophys. Res., 111, D12106, doi:10.1029/2005JD006548, 2006.

Buja, L.: CCM processor users' guide (UNICOS version), Technical Note TN-384+IA, National Center for Atmospheric Research, 1993.

Ceppi, P., Hwang, Y.-T., Liu, X., Frierson, D. M. W., and Hartmann, D. L.: The relationship between the ITCZ and the Southern Hemispheric eddy-driven jet, J. Geophys. Res.-Atmos., 118, 5136-5146, doi:10.1002/jgrd.50461, 2013.

Chalmers, N., Highwood, E. J., Hawkins, E., Sutton, R., and Wilcox, L. J.: Aerosol contribution to the rapid warming of nearterm climate under RCP 2.6, Geophys. Res. Lett., 39, L18709, doi:10.1029/2012GL052848, 2012.

Cheng, Y., Lohmann, U., Zhang, J., Luo, Y., Liu, Z., and Lesins, G.: Contribution of changes in sea surface temperature and aerosol loading to the decreasing precipitation trend in southern China, J. Climate, 18, 1381-1390, 2005.

Chiang, J. C. H. and Friedman, A. R.: Extratropical cooling, interhemispheric thermal gradients, and tropical climate change, Annu. Rev. Earth Pl. Sc., 40, 383-412, doi:10.1146/annurevearth-042711-105545, 2012.

Cionni, I., Eyring, V., Lamarque, J. F., Randel, W. J., Stevenson, D. S., Wu, F., Bodeker, G. E., Shepherd, T. G., Shindell, D. T., and Waugh, D. W.: Ozone database in support of CMIP5 simulations: results and corresponding radiative forcing, Atmos. Chem. Phys., 11, 11267-11292, doi:10.5194/acp11-11267-2011, 2011.

Collier, M. A., Rotstayn, L. D., Kim, K.-Y., Hirst, A. C., and Jeffrey, S. J.: Ocean circulation response to anthropogenic-aerosol and greenhouse gas forcing in the CSIRO-Mk3.6 coupled climate model, Aust. Meteorol. Oceanogr. J., 63, 27-39, 2013.

Compo, G. P., Whitaker, J. S., Sardeshmukh, P. D., Matsui, N., Allan, R. J., Yin, X., Gleason, B. E., Vose, R. S., Rutledge, G., Bessemoulin, P., Brönnimann, S., Brunet, M., Crouthamel, R. I., Grant, A. N., Groisman, P. Y., Jones, P. D., Kruk, M. C., Kruger, A. C., Marshall, G. J., Maugeri, M., Mok, H. Y., Nordli, Ø., Ross, T. F., Trigo, R. M., Wang, X. L., Woodruff, S. D., and Worley, S. J.: The Twentieth Century Reanalysis Project, Q. J. Roy. Meteorol. Soc., 137, 1-28, doi:10.1002/qj.776, 2011. 
Cooke, W. F., Liousse, C., Cachier, H., and Feichter, J.: Construction of a $1^{\circ} \times 1^{\circ}$ fossil fuel emission data set for carbonaceous aerosol and implementation and radiative impact in the ECHAM4 model, J. Geophys. Res., 104, 22137-22162, 1999.

Dix, M., Vohralik, P., Bi, D.and Rashid, H. A., Marsland, S. J., O'Farrell, S., Uotila, P., Hirst, A. C., Kowalcyzk, E. A., Sullivan, A., Yan, H., Franklin, C., Sun, Z., Watterson, I. G., Collier, M. A., Noonan, J., Rotstayn, L. D., Stevens, L., Uhe, P., and Puri, K.: The ACCESS coupled model: Documentation of core CMIP5 simulations and initial results, Aust. Meteorol. Oceanogr. J., 63, 83-99, 2013.

Drijfhout, S., Van Oldenborgh, G. J., and Cimatoribus, A.: Is a decline of AMOC causing the warming hole above the North Atlantic in observed and modeled warming patterns?, J. Climate, 25, 8373-8379, doi:10.1175/JCLI-D-12-00490.1, 2012.

Dufresne, J.-L. and Bony, S.: An assessment of the primary sources of spread of global warming estimates from coupled atmosphere ocean models, J. Climate, 21, 5135-5144, doi:10.1175/2008JCLI2239.1, 2008.

Dufresne, J.-L., Foujols, M.-A., Denvil, S., Caubel, A., Marti, O., Aumont, O., Balkanski, Y., Bekki, S., Bellenger, H., Benshila, R., Bony, S., Bopp, L., Braconnot, P., Brockmann, P., Cadule, P., Cheruy, F., Codron, F., Cozic, A., Cugnet, D., de Noblet, N., Duvel, J.-P., Ethé, C., Fairhead, L., Fichefet, T., Flavoni, S., Friedlingstein, P., Grandpeix, J.-Y., Guez, L., Guilyardi, E., Hauglustaine, D., Hourdin, F., Idelkadi, A., Ghattas, J., Joussaume, S., Kageyama, M., Krinner, G., Labetoulle, S., Lahellec, A., Lefebvre, M.-P., Lefevre, F., Levy, C., Li, Z. X., Lloyd, J., Lott, F., Madec, G., Mancip, M., Marchand, M., Masson, S., Meurdesoif, Y., Mignot, J., Musat, I., Parouty, S., Polcher, J., Rio, C., Schulz, M., Swingedouw, D., Szopa, S., Talandier, C., Terray, P., and Viovy, N.: Climate change projections using the IPSL-CM5 Earth System Model: from CMIP3 to CMIP5, Clim. Dynam., 40, 2123-2165, doi:10.1007/s00382-012-1636-1, 2013.

Feichter, J., Kjellström, E., Rodhe, H., Dentener, F., Lelieveld, J., and Roelofs, G.-J.: Simulation of the tropospheric sulfur cycle in a global climate model, Atmos. Environ., 30, 1693-1707, 1996.

Feichter, J., Roeckner, E., Lohmann, U., and Liepert, B.: Nonlinear aspects of the climate response to greenhouse gas and aerosol forcing, J. Climate, 17, 2384-2398, 2004.

Feulner, G., Rahmstorf, S., Levermann, A., and Volkwardt, S.: On the Origin of the Surface Air Temperature Difference Between the Hemispheres in Earths Present-Day Climate, J. Climate, 26, 7136-7150, doi:10.1175/JCLI-D-12-00636.1, 2013.

Forster, P., Ramaswamy, V., Artaxo, P., Berntsen, T., Betts, R., Fahey, D., Haywood, J., Lean, J., Lowe, D., Myhre, G., Nganga, J., Prinn, R., Raga, G., Schulz, M., and Dorland, R. V.: Changes in atmospheric constituents and in radiative forcing, in: Climate Change 2007: The Physical Science Basis. Contribution of Working Group I to the Fourth Assessment Report of the Intergovernmental Panel on Climate Change, edited by: Solomon, S., Qin, D., Manning, M., Chen, Z., Marquis, M., Averyt, K. B., Tignor, M., and Miller, H. L., Cambridge University Press, Cambridge, UK and New York, NY, USA, 2007.

Forster, P. M., Andrews, T., Good, P., Gregory, J. M., Jackson, L. S., and Zelinka, M.: Evaluating adjusted forcing and model spread for historical and future scenarios in the CMIP5 generation of climate models, J. Geophys. Res.-Atmos., 118, 1139-1150, doi:10.1002/jgrd.50174, 2013.
Gillett, N. P. and Von Salzen, K.: The role of reduced aerosol precursor emissions in driving near-term warming, Environ. Res. Lett., 8, 034008, doi:10.1088/1748-9326/8/3/034008, 2013.

Gordon, H. B., Rotstayn, L. D., McGregor, J. L., Dix, M. R., Kowalczyk, E. A., O'Farrell, S. P., Waterman, L. J., Hirst, A. C., Wilson, S. G., Collier, M. A., Watterson, I. G., and Elliott, T. I.: The CSIRO Mk3 Climate System Model, Technical Paper No. 60, CSIRO Atmospheric Research, Aspendale, Vic., Australia, 134 pp., available at: http://www.cmar.csiro.au/e-print/open/gordon_ 2002a.pdf, 2002.

Gordon, H. B., O'Farrell, S. P., Collier, M. A., Dix, M. R., Rotstayn, L. D., Kowalczyk, E. A., Hirst, A. C., and Watterson, I. G.: The CSIRO Mk3.5 Climate Model, Technical Report No. 21, The Centre for Australian Weather and Climate Research, Aspendale, Vic., Australia, 62 pp., available at: http://www.cawcr. gov.au/publications/technicalreports.php, 2010.

Guenther, A., Hewitt, C. N., Erickson, D., Fall, R., Geron, C., Graedel, T., Harley, P., Klinger, L., Lerdau, M., McKay, W. A., Pierce, T., Scholes, B., Steinbrecher, R., Tallamraju, R., Taylor, J., and Zimmerman, P.: A global model of natural volatile organic compound emissions, J. Geophys. Res., 100, 8873-8892, 1995.

Hansen, J., Sato, M., Ruedy, R., Lo, K., Lea, D. W., and MedinaElizade, M.: Global temperature change, P. Natl. Acad. Sci. USA, 103, 14288-14293, doi:10.1073/pnas.0606291103, 2006.

Hansen, J., Sato, M., Kharecha, P., and von Schuckmann, K.: Earth's energy imbalance and implications, Atmos. Chem. Phys., 11, 13421-13449, doi:10.5194/acp-11-13421-2011, 2011.

Hwang, Y.-T., Frierson, D. M. W., and Kang, S. M.: Anthropogenic sulfate aerosol and the southward shift of tropical precipitation in the late 20th century, Geophys. Res. Lett., 40, 2845-2850, doi:10.1002/grl.50502, 2013.

IPCC: Working Group I Contribution to the IPCC Fifth Assessment Report Climate Change 2013: The Physical Science Basis. Summary for Policymakers, Intergovernmental Panel on Climate Change, 2013.

Iversen, T., Bentsen, M., Bethke, I., Debernard, J. B., Kirkevåg, A., Seland, Ø., Drange, H., Kristjansson, J. E., Medhaug, I., Sand, M., and Seierstad, I. A.: The Norwegian Earth System Model, NorESM1-M - Part 2: Climate response and scenario projections, Geosci. Model Dev., 6, 389-415, doi:10.5194/gmd6-389-2013, 2013.

Jeffrey, S. J., Rotstayn, L. D., Collier, M. A., Dravitzki, S. M., Hamalainen, C., Moeseneder, C., Wong, K. K., and Syktus, J. I.: Australia's CMIP5 submission using the CSIRO-Mk3.6 model, Aust. Meteorol. Oceanogr. J., 63, 1-13, http://www.bom.gov.au/ amoj/docs/2013/jeffrey_hres.pdf, 2013.

Jiang, H., Xue, H., Teller, A., Feingold, G., and Levin, Z.: Aerosol effects on the lifetime of shallow cumulus, Geophys. Res. Lett., 33, L14806, doi:10.1029/2006GL026024, 2006.

Jones, A., Roberts, D. L., Woodage, M. J., and Johnson, C. E.: Indirect sulphate aerosol forcing in a climate model with an interactive sulphur cycle, J. Geophys. Res., 106, 20293-20310, 2001.

Jones, C. D., Hughes, J. K., Bellouin, N., Hardiman, S. C., Jones, G. S., Knight, J., Liddicoat, S., O'Connor, F. M., Andres, R. J., Bell, C., Boo, K.-O., Bozzo, A., Butchart, N., Cadule, P., Corbin, K. D., Doutriaux-Boucher, M., Friedlingstein, P., Gornall, J., Gray, L., Halloran, P. R., Hurtt, G., Ingram, W. J., Lamarque, J.-F., Law, R. M., Meinshausen, M., Osprey, S., 
Palin, E. J., Parsons Chini, L., Raddatz, T., Sanderson, M. G., Sellar, A. A., Schurer, A., Valdes, P., Wood, N., Woodward, S., Yoshioka, M., and Zerroukat, M.: The HadGEM2-ES implementation of CMIP5 centennial simulations, Geosci. Model Dev., 4, 543-570, doi:10.5194/gmd-4-543-2011, 2011.

Jones, G. S., Stott, P. A., and Christidis, N.: Attribution of observed historical near surface temperature variations to anthropogenic and natural causes using CMIP5 simulations, J. Geophys. Res., 118, 4001-4024, doi:10.1002/jgrd.50239, 2013.

Kang, S. M., Frierson, D. M. W., and Held, I. M.: The tropical response to extratropical thermal forcing in an idealized GCM: the importance of radiative feedbacks and convective parameterization, J. Atmos. Sci., 66, 2812-2827, doi:10.1175/2009JAS2924.1, 2009.

Kawase, H., Abe, M., Yamada, Y., Takemura, T., Yokohata, T., and Nozawa, T.: Physical mechanism of long-term drying trend over tropical North Africa, Geophys. Res. Lett., 37, L09706, doi:10.1029/2010GL043038, 2010.

Kettle, A. J. and Andreae, M. O.: Flux of dimethylsulfide from the oceans: a comparison of updated data sets and flux models, J. Geophys. Res., 105, 26793-26808, 2000.

Kinne, S., Schulz, M., Textor, C., Guibert, S., Balkanski, Y., Bauer, S. E., Berntsen, T., Berglen, T. F., Boucher, O., Chin, M., Collins, W., Dentener, F., Diehl, T., Easter, R., Feichter, J., Fillmore, D., Ghan, S., Ginoux, P., Gong, S., Grini, A., Hendricks, J., Herzog, M., Horowitz, L., Isaksen, I., Iversen, T., Kirkevåg, A., Kloster, S., Koch, D., Kristjansson, J. E., Krol, M., Lauer, A., Lamarque, J. F., Lesins, G., Liu, X., Lohmann, U., Montanaro, V., Myhre, G., Penner, J., Pitari, G., Reddy, S., Seland, O., Stier, P., Takemura, T., and Tie, X.: An AeroCom initial assessment - optical properties in aerosol component modules of global models, Atmos. Chem. Phys., 6, 1815-1834, doi:10.5194/acp-6-1815-2006, 2006.

Kirkevåg, A., Iversen, T., Seland, Ø., Hoose, C., Kristjánsson, J. E., Struthers, H., Ekman, A. M. L., Ghan, S., Griesfeller, J., Nilsson, E. D., and Schulz, M.: Aerosol-climate interactions in the Norwegian Earth System Model - NorESM1-M, Geosci. Model Dev., 6, 207-244, doi:10.5194/gmd-6-207-2013, 2013.

Klimont, Z., Smith, S. J., and Cofala, J.: The last decade of global anthropogenic sulfur dioxide: 2000-2011 emissions, Environ. Res. Lett., 8, 014003, doi:10.1088/1748-9326/8/1/014003, 2013.

Kloster, S., Dentener, F., Feichter, J., Raes, F., Lohmann, U., Roeckner, E., and Fischer-Bruns, I.: A GCM study of future climate response to aerosol pollution reductions, Clim. Dynam., 34, 11771194, doi:10.1007/s00382-009-0573-0, 2010.

Koch, D., Schulz, M., Kinne, S., McNaughton, C., Spackman, J. R., Balkanski, Y., Bauer, S., Berntsen, T., Bond, T. C., Boucher, O., Chin, M., Clarke, A., De Luca, N., Dentener, F., Diehl, T., Dubovik, O., Easter, R., Fahey, D. W., Feichter, J., Fillmore, D., Freitag, S., Ghan, S., Ginoux, P., Gong, S., Horowitz, L., Iversen, T., Kirkevåg, A., Klimont, Z., Kondo, Y., Krol, M., Liu, X., Miller, R., Montanaro, V., Moteki, N., Myhre, G., Penner, J. E., Perlwitz, J., Pitari, G., Reddy, S., Sahu, L., Sakamoto, H., Schuster, G., Schwarz, J. P., Seland, Ø., Stier, P., Takegawa, N., Takemura, T., Textor, C., van Aardenne, J. A., and Zhao, Y.: Evaluation of black carbon estimations in global aerosol models, Atmos. Chem. Phys., 9, 9001-9026, doi:10.5194/acp-9-9001-2009, 2009.
Komuro, Y., Suzuki, T., Sakamoto, T. T., Hasumi, H., Ishii, M., Watanabe, M., Nozawa, T., Yokuhata, T., Nishimura, T., Ogochi, K., Emori, S., and Kimoto, M.: Sea-ice in twentiethcentury simulations by new MIROC coupled models: a comparison between models with high resolution and with ice thickness distribution, J. Meteorol. Soc. Jpn., 90A, 213-232, doi:10.2151/jmsj.2012-A11, 2012.

Lamarque, J.-F., Bond, T. C., Eyring, V., Granier, C., Heil, A., Klimont, Z., Lee, D., Liousse, C., Mieville, A., Owen, B., Schultz, M. G., Shindell, D., Smith, S. J., Stehfest, E., Van Aardenne, J., Cooper, O. R., Kainuma, M., Mahowald, N., McConnell, J. R., Naik, V., Riahi, K., and van Vuuren, D. P.: Historical (1850-2000) gridded anthropogenic and biomass burning emissions of reactive gases and aerosols: methodology and application, Atmos. Chem. Phys., 10, 7017-7039, doi:10.5194/acp10-7017-2010, 2010.

Lamarque, J.-F., Kyle, G. P., Meinshausen, M., Riahi, K., Smith, S. J., Vuuren, D. P., Conley, A. J., and Vitt, F.: Global and regional evolution of short-lived radiatively-active gases and aerosols in the Representative Concentration Pathways, Climatic Change, 109, 191-212, doi:10.1007/s10584-011-0155-0, 2011.

Lee, S., Kim, H. K., Yan, B., Cobb, C. E., Hennigan, C., Nichols, S., Chamber, M., Edgerton, E. S., Jansen, J. J., Hu, Y., Zheng, M., Weber, R. J., and Russell, A. G.: Diagnosis of aged prescribed burning plumes impacting an urban area, Environ. Sci. Technol., 42, 1438-1444, doi:10.1021/es7023059, 2008.

Levy II, H., Horowitz, L. W., Schwarzkopf, M. D., Ming, Y., Golaz, J.-C., Naik, V., and Ramaswamy, V.: The roles of aerosol direct and indirect effects in past and future climate change, J. Geophys. Res.-Atmos., 118, 4521-4532, doi:10.1002/jgrd.50192, 2013.

Libardoni, A. G. and Forest, C. E.: Sensitivity of distributions of climate system properties to the surface temperature dataset, Geophys. Res. Lett., 38, L22705, doi:10.1029/2011GL049431, 2011.

Liepert, B. G., Feichter, J., Lohmann, U., and Roeckner, E.: Can aerosols spin down the water cycle in a warmer and moister world?, Geophys. Res. Lett., 31, L06207, doi:10.1029/2003GL019060, 2004.

Liu, X., Xie, X., Yin, Z.-Y., Liu, C., and Gettelman, A.: A modeling study of the effects of aerosols on clouds and precipitation over East Asia, Theor. Appl. Climatol., 106, 343-354, doi:10.1007/s00704-011-0436-6, 2011.

Liu, Z., Vavrus, S., He, F., Wen, N., and Zhong, Y.: Rethinking tropical ocean response to global warming: the enhanced equatorial warming, J. Climate, 18, 4684-4700, doi:10.1175/JCLI3579.1, 2005.

The HadGEM2 Development Team: G. M. Martin, Bellouin, N., Collins, W. J., Culverwell, I. D., Halloran, P. R., Hardiman, S. C., Hinton, T. J., Jones, C. D., McDonald, R. E., McLaren, A. J., O'Connor, F. M., Roberts, M. J., Rodriguez, J. M., Woodward, S., Best, M. J., Brooks, M. E., Brown, A. R., Butchart, N., Dearden, C., Derbyshire, S. H., Dharssi, I., Doutriaux-Boucher, M., Edwards, J. M., Falloon, P. D., Gedney, N., Gray, L. J., Hewitt, H. T., Hobson, M., Huddleston, M. R., Hughes, J., Ineson, S., Ingram, W. J., James, P. M., Johns, T. C., Johnson, C. E., Jones, A., Jones, C. P., Joshi, M. M., Keen, A. B., Liddicoat, S., Lock, A. P., Maidens, A. V., Manners, J. C., Milton, S. F., Rae, J. G. L., Ridley, J. K., Sellar, A., Senior, C. A., Totterdell, I. J., Verhoef, A., 
Vidale, P. L., and Wiltshire, A.: The HadGEM2 family of Met Office Unified Model climate configurations, Geosci. Model Dev., 4, 723-757, doi:10.5194/gmd-4-723-2011, 2011.

Meehl, G. A., Arblaster, J. M., and Collins, W. D.: Effects of black carbon aerosols on the Indian monsoon, J. Climate, 21, 28692882, doi:10.1175/2007JCLI1777.1, 2008.

Menon, S., Hansen, J., Nazarenko, L., and Luo, Y.: Climate effects of black carbon aerosols in China and India, Science, 297, 22502253, 2002.

Ming, Y. and Ramaswamy, V.: Nonlinear climate and hydrological responses to aerosol effects, J. Climate, 22, 1329-1339, doi:10.1175/2008JCLI2362.1, 2009.

Ming, Y. and Ramaswamy, V.: A model investigation of aerosolinduced changes in tropical circulation, J. Climate, 24, 51255133, doi:10.1175/2011JCLI4108.1, 2011.

Ming, Y., Ramaswamy, V., and Persad, G.: Two opposing effects of absorbing aerosols on global-mean precipitation, Geophys. Res. Lett., 37, L13701, doi:10.1029/2010GL042895, 2010.

Morice, C. P., Kennedy, J. J., Rayner, N. A., and Jones, P. D.: Quantifying uncertainties in global and regional temperature change using an ensemble of observational estimates: the HadCRUT4 data set, J. Geophys. Res., 117, D08101, doi:10.1029/2011JD017187, 2012.

Nakicenovic, N., Alcamo, J., Davis, G., de Vries, B., Fenhann, J., Gaffin, S., Gregory, K., Grubler, A., Jung, T. Y., Kram, T., Rovere, E. L. L., Michaelis, L., Mori, S., Morita, T., Pepper, W., Pitcher, H., Price, L., Riahi, K., Roehrl, A., Rogner, H.-H., Sankovski, A., Schlesinger, M., Shukla, P., Smith, S., Swart, R., van Rooijen, S., Victor, N., and Dadi, Z.: Emissions Scenarios. Special Report of the Intergovernmental Panel on Climate Change, Cambridge University Press, Cambridge, UK, 570 pp., 2000 .

O'Gorman, P. A. and Muller, C. J.: How closely do changes in surface and column water vapor follow Clausius-Clapeyron scaling in climate change simulations?, Environ. Res. Lett., 5, 025207, doi:10.1088/1748-9326/5/2/025207, 2010.

O’Gorman, P. A., Allan, R. P., Byrne, M. P., and Previdi, M.: Energetic constraints on precipitation under climate change, Surv. Geophys., 33, 585-608, doi:10.1007/s10712-011-9159-6, 2012.

Quaas, J., Ming, Y., Menon, S., Takemura, T., Wang, M., Penner, J. E., Gettelman, A., Lohmann, U., Bellouin, N., Boucher, O., Sayer, A. M., Thomas, G. E., McComiskey, A., Feingold, G., Hoose, C., Kristjánsson, J. E., Liu, X., Balkanski, Y., Donner, L. J., Ginoux, P. A., Stier, P., Grandey, B., Feichter, J., Sednev, I., Bauer, S. E., Koch, D., Grainger, R. G., Kirkevåg, A., Iversen, T., Seland, Ø., Easter, R., Ghan, S. J., Rasch, P. J., Morrison, H., Lamarque, J.-F., Iacono, M. J., Kinne, S., and Schulz, M.: Aerosol indirect effects - general circulation model intercomparison and evaluation with satellite data, Atmos. Chem. Phys., 9, 8697-8717, doi:10.5194/acp-98697-2009, 2009.

Ramanathan, V., Chung, C., Kim, D., Bettge, T., Buja, L., Kiehl, J. T., Washington, W. M., Fu, Q., Sikka, D. R., and Wild, M.: Atmospheric brown clouds: impacts on South Asian climate and hydrological cycle, P. Natl. Acad. Sci. USA, 102, 5326-5333, 2005.

Roderick, M. L. and Farquhar, G. D.: The cause of decreased pan evaporation over the past 50 years, Science, 298, 1410-1411, 2002.
Rotstayn, L. D.: A physically based scheme for the treatment of stratiform clouds and precipitation in large-scale models. I: Description and evaluation of the microphysical processes, Q. J. Roy. Meteor. Soc., 123, 1227-1282, 1997.

Rotstayn, L. D.: Climate sensitivity of the CSIRO GCM: Effect of cloud modeling assumptions, J. Climate, 12, 334-356, 1999.

Rotstayn, L. D. and Liu, Y.: A smaller global estimate of the second indirect aerosol effect, Geophys. Res. Lett., 32, L05708, doi:10.1029/2004GL021922, 2005.

Rotstayn, L. D. and Liu, Y.: Cloud droplet spectral dispersion and the indirect aerosol effect: comparison of two treatments in a GCM, Geophys. Res. Lett., 36, L10801, doi:10.1029/2009GL038216, 2009.

Rotstayn, L. D. and Lohmann, U.: Tropical rainfall trends and the indirect aerosol effect, J. Climate, 15, 2103-2116, doi:10.1175/1520-0442(2002)015<2103:TRTATI>2.0.CO;2, $2002 a$.

Rotstayn, L. D. and Lohmann, U.: Simulation of the tropospheric sulfur cycle in a global model with a physically based cloud scheme, J. Geophys. Res., 107, 4592, doi:10.1029/2002JD002128, 2002b.

Rotstayn, L. D., Ryan, B. F., and Penner, J. E.: Precipitation changes in a GCM resulting from the indirect effects of anthropogenic aerosols, Geophys. Res. Lett., 27, 3045-3048, doi:10.1029/2000GL011737, 2000.

Rotstayn, L. D., Cai, W., Dix, M. R., Farquhar, G. D., Feng, Y., Ginoux, P., Herzog, M., Ito, A., Penner, J. E., Roderick, M. L., and Wang, M.: Have Australian rainfall and cloudiness increased due to the remote effects of Asian anthropogenic aerosols?, J. Geophys. Res., 112, D09202, doi:10.1029/2006JD007712, 2007.

Rotstayn, L. D., Collier, M. A., Mitchell, R. M., Qin, Y., Campbell, S. K., and Dravitzki, S. M.: Simulated enhancement of ENSO-related rainfall variability due to Australian dust, Atmos. Chem. Phys., 11, 6575-6592, doi:10.5194/acp-11-6575-2011, 2011.

Rotstayn, L. D., Jeffrey, S. J., Collier, M. A., Dravitzki, S. M., Hirst, A. C., Syktus, J. I., and Wong, K. K.: Aerosol- and greenhouse gas-induced changes in summer rainfall and circulation in the Australasian region: a study using single-forcing climate simulations, Atmos. Chem. Phys., 12, 6377-6404, doi:10.5194/acp12-6377-2012, 2012.

Rotstayn, L. D., Collier, M. A., Jeffrey, S. J., Kidston, J., Syktus, J. I., and Wong, K. K.: Anthropogenic effects on the subtropical jet in the Southern Hemisphere: aerosols versus long-lived greenhouse gases, Environ. Res. Lett., 8, 014030, doi:10.1088/1748-9326/8/1/014030, 2013.

Sandu, I., Brenguier, J.-L., Geoffroy, O., Thouron, O., and Masson, V.: Aerosol impacts on the diurnal cycle of marine stratocumulus, J. Atmos. Sci., 65, 2705-2718, doi:10.1175/2008JAS2451.1, 2008.

Sato, M., Hansen, J. E., McCormick, M. P., and Pollack, J. B.: Stratospheric aerosol optical depth, 1850-1990, J. Geophys. Res., 98, 22987-22994, 1993.

Schulz, M., Textor, C., Kinne, S., Balkanski, Y., Bauer, S., Berntsen, T., Berglen, T., Boucher, O., Dentener, F., Guibert, S., Isaksen, I. S. A., Iversen, T., Koch, D., Kirkevåg, A., Liu, X., Montanaro, V., Myhre, G., Penner, J. E., Pitari, G., Reddy, S., Seland, Ø., Stier, P., and Takemura, T.: Radiative forcing by aerosols as derived from the AeroCom present-day and pre-industrial simulations, 
Atmos. Chem. Phys., 6, 5225-5246, doi:10.5194/acp-6-52252006, 2006.

Sherwood, S. C., Ingram, W., Tsushima, Y., Satoh, M., Roberts, M., Vidale, P. L., and O'Gorman, P. A.: Relative humidity changes in a warmer climate, J. Geophys. Res., 115, D09104, doi:10.1029/2009JD012585, 2010.

Shindell, D. T., Lamarque, J.-F., Schulz, M., Flanner, M., Jiao, C., Chin, M., Young, P. J., Lee, Y. H., Rotstayn, L., Mahowald, N., Milly, G., Faluvegi, G., Balkanski, Y., Collins, W. J., Conley, A. J., Dalsoren, S., Easter, R., Ghan, S., Horowitz, L., Liu, X., Myhre, G., Nagashima, T., Naik, V., Rumbold, S. T., Skeie, R., Sudo, K., Szopa, S., Takemura, T., Voulgarakis, A., Yoon, J.-H., and Lo, F.: Radiative forcing in the ACCMIP historical and future climate simulations, Atmos. Chem. Phys., 13, 2939-2974, doi:10.5194/acp-13-2939-2013, 2013a.

Shindell, D. T., Pechony, O., Voulgarakis, A., Faluvegi, G., Nazarenko, L., Lamarque, J.-F., Bowman, K., Milly, G., Kovari, B., Ruedy, R., and Schmidt, G. A.: Interactive ozone and methane chemistry in GISS-E2 historical and future climate simulations, Atmos. Chem. Phys., 13, 2653-2689, doi:10.5194/acp13-2653-2013, 2013b.

Shine, K. P., Cook, J., Highwood, E. J., and Joshi, M. M.: An alternative to radiative forcing for estimating the relative importance of climate change mechanisms, Geophys. Res. Lett, 30, 2047, doi:10.1029/2003GL018141, 2003.

Smith, S. J. and Bond, T. C.: Two hundred fifty years of aerosols and climate: the end of the age of aerosols, Atmos. Chem. Phys. Discuss., 13, 6419-6453, doi:10.5194/acpd-13-6419-2013, 2013.

Smith, S. J., van Aardenne, J., Klimont, Z., Andres, R. J., Volke, A., and Delgado Arias, S.: Anthropogenic sulfur dioxide emissions: 1850-2005, Atmos. Chem. Phys., 11, 1101-1116, doi:10.5194/acp-11-1101-2011, 2011.

Szopa, S., Balkanski, Y., Schulz, M., Bekki, S., Cugnet, D., Fortems-Cheiney, A., Turquety, S., Cozic, A., Déandreis, C., Hauglustaine, D., Idelkadi, A., Lathiére, J., Lefevre, F., Marchand, M., Vuolo, R., Yan, N., and Dufresne, J.-L.: Aerosol and ozone changes as forcing for climate evolution between 1850 and 2100, Clim. Dynam., 40, 1-28, doi:10.1007/s00382-012-1408-y, 2013.

Taylor, K. E., Stouffer, R. J., and Meehl, G. A.: An overview of CMIP5 and the experiment design, B. Am. Meteorol. Soc., 93, 485-498, doi:10.1175/BAMS-D-11-00094.1, 2012.

Thomson, A. M., Calvin, K. V., Smith, S. J., Kyle, G. P., Volke, A., Patel, P., Delgado-Arias, S., Bond-Lamberty, B., Wise, M. A., Clarke, L. E., and Edmonds, J. A.: RCP4.5: A pathway for stabilization of radiative forcing by 2100 , Climatic Change, 109, 77-94, doi:10.1007/s10584-011-0151-4, 2011.
Van Vuuren, D. P., Edmonds, J., Kainuma, M., Riahi, K., Thomson, A., Hibbard, K., Hurtt, G. C., Kram, T., Krey, V., Lamarque, J.-F., Masui, T., Meinshausen, M., Nakicenovic, N., Smith, S. J., and Rose, S. K.: The representative concentration pathways: an overview, Climatic Change, 109, 5-31, doi:10.1007/s10584-011-0148-z, 2011.

Villarini, G. and Vecchi, G. A.: Twenty-first-century projections of North Atlantic tropical storms from CMIP5 models, Nature Climate Change, 2, 604-607, doi:10.1038/nclimate1530, 2012.

von Salzen, K., Scinocca, J. F., McFarlane, N. A., Li, J., Cole, J. N. S., Plummer, D., Verseghy, D., Reader, M. C., Ma, X., Lazare, M., and Solheim, L.: The Canadian Fourth Generation Atmospheric Global Climate Model (CanAM4). Part I: Representation of physical processes, Atmos. Ocean, 51, 104-125, doi:10.1080/07055900.2012.755610, 2013.

Watanabe, M., Suzuki, T., O'Ishi, R., Komuro, Y., Watanabe, S., Emori, S., Takemura, T., Chikira, M., Ogura, T., Sekiguchi, M., Takata, K., Yamazaki, D., Yokohata, T., Nozawa, T., Hasumi, H., Tatebe, H., and Kimoto, M.: Improved climate simulation by MIROC5: mean states, variability, and climate sensitivity, J. Climate, 23, 6312-6335, doi:10.1175/2010JCLI3679.1, 2010.

Weaver, A. J. Sedláček, J., Eby, M., Alexander, K., Crespin, E., Fichefet, T., Philippon-Berthier, G., Joos, F., Kawamiya, M., Matsumoto, K., Steinacher, M., Tachiiri, K., Tokos, K., Yoshimori, M., and Zickfeld, K.: Stability of the Atlantic meridional overturning circulation: a model intercomparison, Geophys. Res. Lett., 39, L20709, doi:10.1029/2012GL053763, 2012.

Wigley, T. M. L.: Possible climate change due to $\mathrm{SO}_{2-}$ derived cloud condensation nuclei, Nature, 339, 365-367, doi:10.1038/339365a0, 1989.

Williams, K. D., Jones, A., Roberts, D. L., Senior, C. A., and Woodage, M. J.: The response of the climate system to the indirect effects of anthropogenic sulfate aerosol, Clim. Dynam., 17, 845-856, 2001.

Xin, X., Wu, T., Li, J., Wang, Z., Li, W., and Wu, F.: How well does BCC_CSM1.1 reproduce the 20th century climate change over China?, Atmos. Ocean. Sci. Lett., 6, 21-26, 2013 a.

Xin, X., Zhang, L., Zhang, J., Wu, T., and Fang, Y.: Climate change projections over East Asia with BCC_CSM1.1 climate model under RCP scenarios, J. Meteorol. Soc. Jpn., in press, 2013b.

Yukimoto, S., Adachi, Y., Hosaka, M., Sakami, T., Yoshimura, H., Hirabara, M., Tanaka, T., Shindo, E., Tsujino, H., Deushi, M., Mizuta, R., Yabu, S., Obata, A., Nakano, H., Koshiro, T., Ose, T., and Kitoh, A.: A new global climate model of the Meteorological Research Institute: MRI-CGCM3 - model description and basic performance, J. Meteorol. Soc. Jpn., 90A, 23-64, doi:10.2151/jmsj.2012-A02, 2012. 